\title{
Slot-Die Coating of Perovskite Solar Cells: An Overview
}

\author{
Rahul Patidar, Daniel Burkitt, Katherine Hooper, David Richards, Trystan Watson \\ SPECIFIC, Baglan Bay Innovation Centre, Central Avenue, Baglan, Port Talbot, SA12 7AX.
}

\begin{abstract}
To make perovskite solar cells an industrially relevant technology large area deposition techniques are needed and one of the most promising is slot-die coating. This review article details the progress reported in the literature where slot-die coating has been used for the deposition of both the perovskite layer and other layers in the perovskite solar cell device stack. An overview of the methods used to adapt the coating process, materials and drying conditions in order to create high quality layers and devices is given and an outlook on future research directions in this field is made.
\end{abstract}

Keywords: Slot-die Coating, Perovskite Solar Cell, Manufacturing, Photovoltaics, Roll-to-Roll

\section{Introduction}

The remarkable opto-electronic properties of lead halide perovskites coupled with the advancements in thin film photo- 40 voltaic device fabrication generated from organic photovoltaic ${ }_{41}$ (OPV) and dye sensitised solar cell (DSSC) research has pro- 42 pelled perovskite solar cells (PSC) to astonishing power con- 43 version efficiencies (PCEs) and the forefront of next generation ${ }_{44}$ photovoltaics research. In under a decade PCEs rose from $3.8 \% 45$ in 2009 to certified $24.2 \%$ as of July 2019 , outperforming well 46 established technologies like multicrystalline silicon and cop- 47 per indium gallium selenide solar cells (CIGS) $[1,2,3,4,5] . \quad 48$

PSCs show great potential in becoming a disruptive technol- 49 ogy in the photovoltaics industry, however, there are many chal- 50 lenges yet to overcome to bring this technology to the market. 51 For instance, bridging the 'scaling gap' and transitioning PSCs 52 from a lab scale to an industrial scale is a serious challenge [6]. Compatibility with flexible substrates and devices and the potential for high throughput roll-to-roll (R2R) manufacture that this offers is one of the key features that makes the case for using PSCs compelling. R2R fabrication not only offers the possibility of manufacturing at far higher speeds than those possible for conventional silicon photovoltaics but also offers the opportunity to deploy modules at unprecedented rates and in novel formats, as demonstrated for structurally similar organic photovoltaics $[7,8]$.

Efforts are being made to upscale the technology with a variety of techniques having been employed for the fabrication of large area PSCs, utilising both solution based and vacuum deposition methods. The most common are spin coating, blade coating [9], screen printing [10], spray coating [11, 12], slotdie coating, gravure printing [13] and vacuum deposition [14]. It could be argued that, to date, the most successful of these ${ }_{53}$ is blade coating where it has been used for the deposition of 54 the perovskite layer in modules with PCEs of over $15 \%$ and ${ }_{55}$ an aperture area of $30 \mathrm{~cm}^{2}$ [15]. Blade coating of perovskites 56 has only been reported for small scale bench-top sheet-to-sheet 57
(S2S) fabrication and not for R2R processes. Only gravure [13] and slot-die coating [16, 17, 18, 19, 20, 21] have been reported for use in R2R deposition processes for the perovskite layer of the device stack, with slot-die coating resulting in devices achieving both high PCEs and line speeds on flexible glass [20] and plastic substrates [19].

Slot-die coating is well suited for the deposition of perovskite inks, as well as other layers in the device stack. As a premetered coating method, it is highly efficient in terms of materials usage and results in very low wastage levels of inks compared to other deposition methods such as spin coating or spray and screen printing. For a typical slot-die coating process a coating head is positioned close to and across a substrate or web, ink is then pumped into the head, using a syringe pump, with the ink forced out of a narrow slit along the length of the coating head (Figure 1).

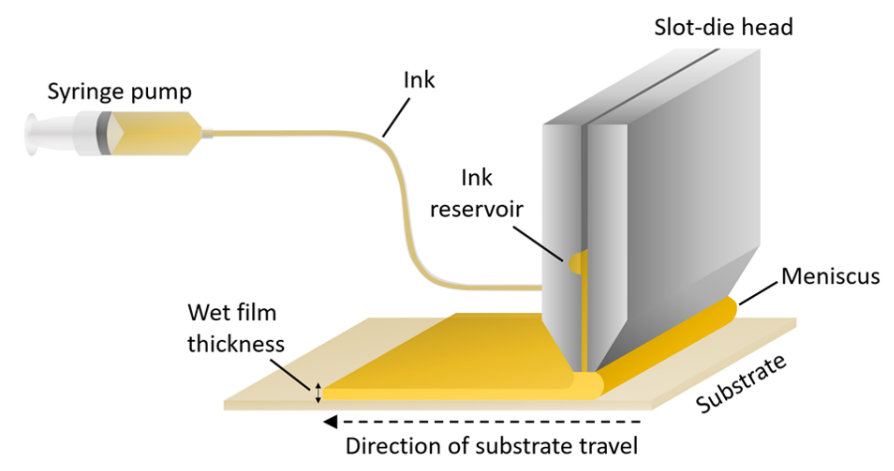

Figure 1: Schematic of a slot-die coating process, showing the delivery of ink to the head from a syringe pump and formation of an ink wet film between the coating head lips and the substrate.

The ink forms a liquid bridge between the coating head and the substrate whereby when the substrate is moved past the head, the deposition of a wet film is achieved. Over a given coating width the thickness of the dry film deposited is controlled by adjusting the flow of ink to the coating head and the 
speed at which the substrate moves past the head. This directly ${ }_{10}$ translates to changes in the wet film thickness and subsequently after drying the dry film thickness. This allows for very fine ${ }_{110}$ control of the dry film thickness, to within a few nm, as well as ${ }_{11}$ the ability to deposit very thin dry films, of tens of nm, up to ${ }_{112}$ much thicker films of tens of microns simply by adjusting the ${ }_{113}$ ink flow rate or substrate speed.

There are a number of common failure mechanisms for slot-115 die coatings including (i) the 'low-flow' limit [22], where the ${ }_{116}$ breakup of the downstream meniscus causes discontinuity in ${ }_{117}$ the wet film (ii) discontinuous film defects such as rivulets,118 where the coating breaks into multiple smaller stripes with gaps (iii) completely discontinuous films where the coating stops and starts along the length of the substrate (iv) air-entrainment defects, associated with the breakup of the upstream meniscus ${ }^{120}$ leading to 'bubbles' within the wet film and areas of uncoated ${ }^{121}$ substrate and (v) 'flooding' or 'dripping' where the flow of ink ${ }^{122}$ to the head is too great compared to the coating speed and re-123 sults in the gradual build-up of ink at the coating head and loss ${ }^{124}$ of pre-metering and the expected film thickness. One of the ${ }^{125}$ most important operating limits is the low-flow limit, which ${ }^{126}$ causes break-up of the down stream meniscus and discontinous ${ }^{127}$ film formation. The capillary number is given by 1 and the low-128 flow limit can be given in terms of a critical capillary number ${ }^{129}$ $\left(\mathrm{Ca}_{\text {low-flow }}\right)$ as in 2 , above which, for a particular gap height and ${ }^{130}$ wet film thickness, the coating is unstable, the low-flow limit is ${ }^{13}$ generally applicable for capillary numbers less than one but de-132 viations can occur for higher capillary numbers. Here $\mu$ is the ${ }^{133}$ viscosity of the ink, $\sigma$ is surface tension, $\mathrm{V}$ is the web speed ${ }^{134}$ or coating speed, $H$ is the gap between substrate and die head 135 and $t$ is the wet film thickness. Therefore, for the set operating ${ }^{136}$ parameters $H$ and $\mathrm{V}$, the ink rheology (surface tension and vis-137 cosity) must be adjusted (or vice-versa) to remain below critical ${ }^{138}$ capillary number ensuring defect free films with right wet film 139 thickness. For a more complete explanation of slot-die coating 140 and common defects the reader is directed to the review article 141 by Harris et al. [23].

$$
C a=\frac{\mu V}{\sigma}
$$

$$
C a_{\text {low-flow }}=\frac{\mu V}{\sigma} \leq 0.65\left(\frac{2}{\frac{H}{t}-1}\right)^{\frac{3}{2}}
$$

Table 1 summarises the device stacks and current density ${ }^{-151}$ voltage (JV) scan photovoltaic performance parameters for per- ${ }^{-152}$ ovskite solar cells with a slot-die coated perovskite layer re- ${ }_{153}$ ported in the literature so far.

In this review, the summary of various approaches developed ${ }_{155}$ to slot-die coat perovskite and other layers of the device stack 156 will be presented. The effects of different coating procedures, 157 additives and drying conditions will be discussed, along with 158 discussion on the fundamental understanding of nucleation and ${ }_{159}$ crystallization of slot-die coated perovskite films. A compre-160 hensive review of the development in the performance of slot-161 die coated perovskite solar cells will be given.

\section{Perovskite Film Formation}

The perovskite layer is the most important layer in the perovskite solar cell device stack, to this end it is vital to have defect free films with large grain size, crystal phase purity and good film coverage that can deliver higher photovoltaic performance and stability. The following sections will discuss the various procedures developed to improve the quality of slot-die coated perovskite layers, all of which are effectively based on controlling the crystallization dynamics of the perovskite material.

\subsection{Two-Step}

The two-step or sequential deposition process for the fabrication of organic-inorganic perovskite layers was first introduced by Mitzi et al. [24] and later further developed for deposition of the active layer in PSCs by Burschka et al. [25]. In this process a pre-deposited lead halide film is exposed to a cation and halide source e.g. methylammonium iodide (MAI) or caesium iodide, that then react together to form the final perovskite. Most typically this is achieved by spin coating a lead iodide $\left(\mathrm{PbI}_{2}\right)$ film that is then dried and exposed to a solution of MAI either by spin coating the solution on top of the $\mathrm{PbI}_{2}$ film or dipping the $\mathrm{PbI}_{2}$ film into a solution of MAI. When this is applied to slotdie coating, the principal of the process is the same, with a $\mathrm{PbI}_{2}$ layer first slot-die coated onto the substrate and the film dried, followed by either slot-die coating of a MAI solution onto the $\mathrm{PbI}_{2}$ layer or dip coating of the $\mathrm{PbI}_{2}$ layer in a MAI solution.

Compared to depositing the perovskite precursors from a single ink in one coating stage, termed a 'one-step' or 'single step' process, the two-step process allows the separation of film formation into distinct parts that might be beneficial to the overall film formation. When considering the formation of the perovskite film, the nucleation and crystal growth of the perovskite from the wet film of the precursor solution is critical to achieving good dry film formation with good overall film coverage. This is particularly challenging when using many of the strongly polar aprotic solvents commonly used for perovskite precursor inks. These inks, which poorly wet on many of the common interlayers, can lead to de-wetting of the substrate as well as the growth of large crystals with large voids, that when fabricated into devices lead to shunt leakages and shorts that are detrimental to performance. This was overcome in spin coated layers by depositing the lead iodide first, separately to the other precursors, which resulted in films with high surface coverage that could then be converted to perovskite to a high degree. Later this was somewhat superseded by the development of the 'anti-solvent' or 'solvent quenching' method [26], where the precursor film is rapidly exposed to a solvent which poorly solvates the precursors and leads to the rapid nucleation of perovskite and almost complete surface coverage. This method can produce excellent film qualities but integrating this into a standard slot-die coating process is difficult. For these reasons many of the first reports of slot-die coated perovskite layers made use of the two-step method, as it can result in high surface coverage. 
Schmidt et al. compared the effects of the two-step deposition with that of one-step on slot-die coated films [27]. The outcome of both approaches was found to be dependent on the device stack and interlayers the precursor solutions were deposited onto, the one-step deposition performed better with ITO/PEDOT: PSS (P-I-N 'inverted' architecture stack) geometry while perovskite would did not form on a ITO/ZnO/PCBM (N-I-P 'standard' architecture stack) geometry. The lower performance with one-step deposition in an N-I-P stack is linked to poor film coverage of the perovskite on top of the electron transport layer (ETL), leading to lower photocurrent [28]. Whereas for two-step deposition perovskite formation was achieved in both device stacks, however the performance of the P-I-N stack devices was very poor. This demonstrates the importance and interplay of the deposition process (one or two-step), the properties of the substrate layer the formulation is being deposited onto. The nucleation and crystallisation of the different precursor solutions in dependent on the substrate surface.

In the two-step deposition process it is important to have highly uniform $\mathrm{PbI}_{2}$ films with high surface coverage, but also films that can be converted to perovskite readily. Contrary to spin coating, the slow drying of the slot-die coated films gives220 enough time for mass transfer and solvent flow to cause non-221 uniformity in the films[29]. Hwang $\mathrm{K}$ et al. reported the im-222 pact of slow drying on slot-die coated $\mathrm{PbI}_{2}$ films in an effort to ${ }^{223}$ deposit the perovskite layer sequentially [16], the formation of 224 highly non-uniform films upon slow drying was noticed, to mit-225 igate the unwanted flow of the ink a process to mimic the spinin 226 coating drying mechanism by externally quenching the films ${ }^{227}$ by a gas jet was employed. A second slot-die coating head was ${ }^{228}$ connected beside the first head and compressed nitrogen gas 229 was flowed on to the just deposited wet film, to speed drying, 230 the 'gas quenched' $\mathrm{PbI}_{2}$ films formed were found to be dense231 and with uniform film coverage. Figure 2 shows the difference232 in the $\mathrm{PbI}_{2}$ film morphology with gas quenching to that of films233 allowed to dry under ambient conditions. The dense lead io-234 dide films formed using this process were found to poorly con-235 vert to perovskite when exposed to MAI. To increase the re-236 activity of the $\mathrm{PbI}_{2}$ films to MAI and obtain full conversion to237 perovskite, a solvent vapour soaking technique was employed. ${ }^{238}$ After drying the gas quenched $\mathrm{PbI}_{2}$ films were stored in an en-239 closed chamber, this resulted in a more porous film that allowed240 complete penetration of MAI and a high degree of conversion ${ }^{241}$ to perovskite, as well as achieving good film coverage with few 242 pin hole formations. As the perovskite layer, the ECL and hole ${ }^{243}$ transport layers (HTL) were deposited using slot-die coating,,244 resulting in a hero cell performance for the complete slot-die 245 coated device of $11.96 \%$ PCE. However, storing the film for 246 long periods to make it more reactive is not an ideal method, ${ }_{247}$ especially for a scaled-up manufacturing process where reduc-248 ing the production time and maximising throughput are critical,249 the process also limits the transition to continuous roll to roll250 fabrication.

In order to develop a more scalable method to produce highly ${ }_{252}$ reactive $\mathrm{PbI}_{2}$ films the same group reported using a method, 253 previously demonstrated for spin coated devices $[30,31]$, in-254 volving an unstable perovskite intermediate [18]. A non-255

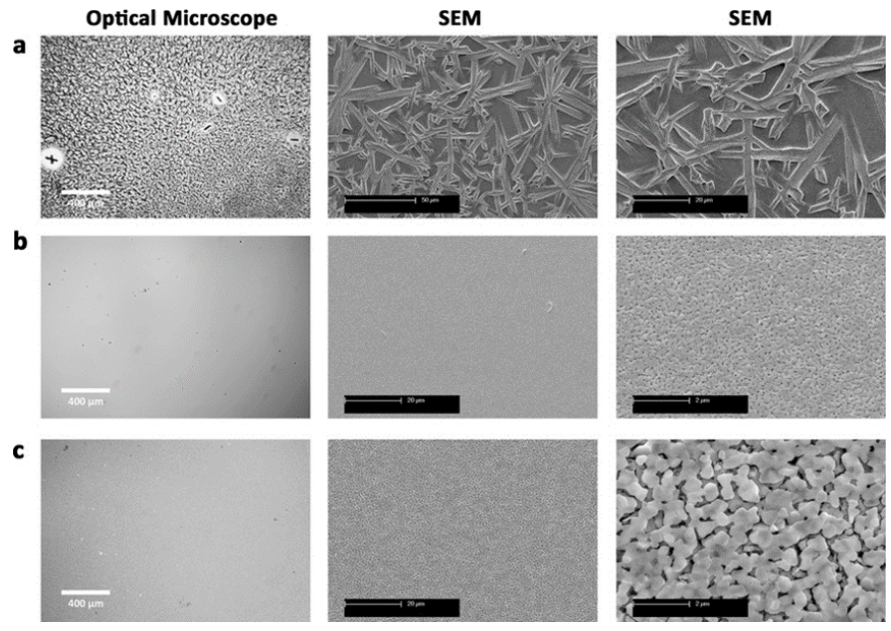

Figure 2: Optical microscopy and SEM images of the slot-die coated $\mathrm{PbI}_{2}$ films by (a) ambient drying (b) gas-quenching and air storage (c) by gas quenching and enclosed space storage. Reproduced with permission from ref [16]. Copyright 2015, Wiley.

stochiometric amount of MAI (referred as intra-addive approach) was added to the $\mathrm{PbI}_{2}$ formulation to slow down the $\mathrm{PbI}_{2}$ crystallization in the first deposition step making it highly reactive at the second step, this subsequently gives greater conversion to the final perovskite. Figure 3 shows the schematic representation of the process. A PCE of $5.8 \%$ was achieved with a R2R processed device on a flexible substrate with evaporated top contacts. To push the PCE further, $\mathrm{CH}_{3} \mathrm{NH}_{2} \mathrm{PbI}_{3}$ was replaced with the double cation perovskite $\left(\mathrm{FA}_{0.4} \mathrm{MA}_{0.6} \mathrm{PbI}_{3}\right)$ whereby $40 \mathrm{~mol} \%$ FAI was used as an additive in the first step along with $\mathrm{PbI}_{2}$ followed by MAI deposition. This increased the PCE to $7.3 \%$ in the same device stack on a flexible substrate and led to a PCE of $11.0 \%$ when the P3HT hole transport layer (HTL) was changed to PEDOT:PSS, (see Figure 3). The similar approach was further used by Gong et al. to deposit triple cation perovksite [32]. The active layer was partially printed by microgravure printing. For the printing of active layer, $\mathrm{PbI}_{2} / \mathrm{CsI}$ films with samll amount of MAI/FAI (as an intra additive) was first printed using microgravure method on top of gravure printed $\mathrm{SnO}_{2}$. This was followed by slot die coating of FAI/MAI mixture for the complete conversion to perovskite. In additon, gas blowing was used to reduce the roughness of the perovksite film resulting in improved performance of the stack. Intra additive approach combined with gas blowing resulted in hero PCE of $10.57 \%$.

Another method, 'mediator extraction treatment' (MET) for the preparation of $\mathrm{PbI}_{2}$ films that result in high quality perovskite layers was reported by $\mathrm{Kim}$ et al. [33]. $\mathrm{A} \mathrm{PbI}_{2}$ ink formulation of lead iodide in Dimthylformamide (DMF) with $10 \%$ vol/vol Dimethyl sulfoxide (DMSO) was first slot-die coated, and then exposed to a gas flow from an air knife. This resulted in a $\mathrm{PbI}_{2}-\mathrm{DMSO}$ complex, which was then dipped in an antisolvent bath to extract DMSO. In the following conversion step, the resulting $\mathrm{PbI}_{2}$ films were dipped in a MAI bath (mixed with $25 \mathrm{wt} \%$ mehylammonium chloride), which once dried, converted to the final perovskite phase. The MET pro- 
a)

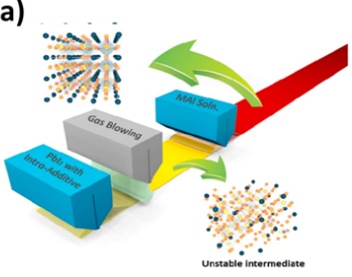

b)

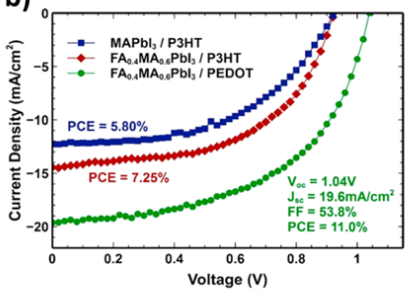

c)

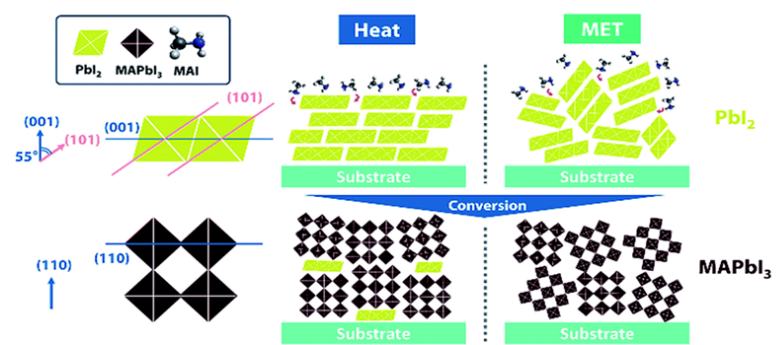

Figure 3: (a) Schematic illustration of the coating procedure (b) JV curve of the R2R coated devices. Reproduced with permission from ref [18]. Copyright ${ }_{307}$ Elsevier, 2017 (c) A schematic illustration showcasing the different $\mathrm{PbI}_{2}$ crys- ${ }^{307}$ tal orientation made by MET and heat treatment and subsequent $\mathrm{CH}_{3} \mathrm{NH}_{3} \mathrm{PbI}_{3}{ }^{308}$ films. Reproduced with permission from ref [33]. Copyright 2018, Royal Soci-309 ety of Chemistry. rectly coating on to this, the $\mathrm{PbI}_{2}$ films were made more reactive to MAI and to give greater levels of conversion to perovskite. The choice of solvent for the MAI ink was also optimised for slot-die coating and ethanol found to be the best of those assessed, this resulted in devices produced with slot-die coated $\mathrm{PbI}_{2}$ and MAI with average PCEs of $11 \%$ and a hero PCE of $13.2 \%$. In another work, the use of these solvent systems was further demonstrated in a R2R process, using a P-I-N device stack with ITO coated PET substrate, PEDOT:PSS HTL and PCBM/BCP ECL and silver top electrode, but the low volatility of the DMSO solvent led to reticulation of the $\mathrm{PbI}_{2}$ film on drying in the R2R ovens. By increasing the drying temperature the film formation was improved, but this resulted in damage to the temperature sensitive substrate and a wide spread in device performance [21].

Two-step deposition has been shown to produce high efficiency small area devices, with PCEs up to $18.3 \%$ and been shown to work in $\mathrm{R} 2 \mathrm{R}$ processes. Key to these results has been speeding the drying of the $\mathrm{PbI}_{2}$ films to improve film uniformity and also using methods that result in films that react readily to form perovskite, either through enclosed chamber storage, mediator extraction treatment, solvent choice or intra-additive approaches. Of these the intra-additive approach has shown great potential for $\mathrm{R} 2 \mathrm{R}$ processing and combined with the developments of MET and safer solvents along with rapid heating methods could deliver a viable R2R process for the slot-die coating of perovskite films.

\subsection{One-Step}

Due to the increased complexity, coating time and potentially lower yield, two-step deposition is not the ideal method for a scaled-up manufacturing process and a one-step process would be preferred. PSCs stacks can be broadly divided into two categories, N-I-P (standard) and P-I-N (inverted). Most of the work to date has reported one-step slot-die coated perovskite in the $\mathrm{P}$ I-N geometry due to improved perovskite film coverage on top of an organic layer e.g. PEDOT:PSS. However, the stability of the P-I-N stack is a concern to commercial development [37]. PEDOT:PSS, the most commonly used HTL in an P-I-N geometry is vulnerable to water. The instability of the ITO/organic interface, the acidic nature of PEDOT and diffusion of PSS are additional reasons that makes this stack prone to faster degradation [38, 39]. But, unlike the N-I-P stack which normally requires high temperature sintering for the metal oxide layer, the P-I-N stack consists of organic layers which are processed at low temperatures and are therefore compatible with plastic substrates, hence are more easily R2R compatible. However, recent developments [40] in low temperature processed metal oxide electron transport layers like tin oxide $\left(\mathrm{SnO}_{2}\right)$ have created a route for N-I-P stacks to be compatible with plastic substrates, as discussed in more detail in Section 4.

\subsubsection{Controlling Film Formation Through Drying Conditions}

For one-step perovskite formulations the device stack of choice was initially the P-I-N, due to the improved film quality, 

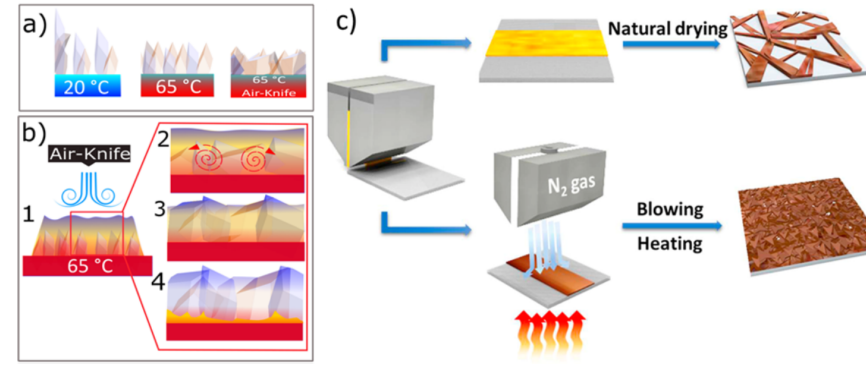

Figure 4: (a) Illustration of layer differences with varying conditions (b) 1. Use of air knife following initial nucleation growth. 2. Convective motions and reduced viscosity boost the crystal growth at the interface with the sub- ${ }^{390}$ strate 3. Crystals approach the cooler region reducing the vertical growth rate 391 in favour of lateral growth across the warm substrate. 4. Reduced thickness is ${ }_{392}$ achieved. Reproduced with permission from ref [41]. Copyright 2016, Elsevier. (c) Schematic representation of the perovskite film formation via slot-die coating under the gas-blowing process combined with substrate heating. $\mathrm{Re}^{-}{ }^{394}$ produced with permission from ref [43]. Copyright 2018, Elsevier. both improved surface coverage and lower surface roughness. Although the absolute PCEs were low, this nonetheless demonstrated substrate heating and drying conditions as an effective way to control perovskite film morphology.

Attempts to control perovskite film formation using drying methods have shown that increasing the nucleation rate of the perovskite film is important for achieving films with high surface coverage and that rapid drying of the solvent can help to avoid the formation of large crystallites and voids within the film.

\subsubsection{Controlling Film Formation Through Precursor Choice}

Rapid crystallization was also implemented by Lee et al., in a P-I-N stack with PEDOT:PSS HTL and $\mathrm{C}_{60}$ /PCBM ETL, using mixed lead precursors in a DMF solvent system, the use of mixed lead acetate and lead chloride precursors in the perovskite ink was demonstrated[45]. Lead acetate induces fast crystallization by forming an unstable organic by-product (methylammonium acetate) [46]. The use of lead acetate as the only $\mathrm{Pb}$ source combined with gas blowing however, caused the rapid crystallization on the surface of the film. This then entrapped the remaining solvent and by-product within the film, causing the formation of voids in the active layer. To avoid this, lead chloride was added alongside lead acetate to retard the rapid crystallization on the surface, avoiding any formation of voids, Figure 5. Using two different lead anion precursors combined with gas blowing improved the grain size, morphology and film coverage and resulted in a PCE of $13.3 \%$ over a small area of $0.1 \mathrm{~cm}^{2}$ and $8.3 \%$ PCE over a $10 \mathrm{~cm}^{2}$ module.

Similar use of lead acetate was made by Kamaraki et al. on flexible ITO coated PET substrates, with slot-die coated PEDOT:PSS HTL and PCBM ETL layers also, using a solely lead acetate precursor in DMF solvent system [47]. The deposition temperature of the perovskite ink was optimised and similar to the work of Ciro et al. [44] resulted in changes in surface roughness. Optimised coating conditions for all three layers resulted in average PCEs of $5 \%$ and a maximum of $6.5 \%$. Notably, Giacomo et al. also used a mixed lead chloride and lead acetate precursor solution in DMF for large area high performance module fabrication in a nitrogen atmosphere glove-box system [48].

Judicious selection of perovskite precursors is another method to control the nucleation and crystallization rate of perovskite films and so improve surface coverage and morphology. When this is combined with methods to control the drying of the films it can result in high performance cells and modules.

\subsubsection{Controlling Film Formation Through Solvent Choice}

Jung et al. demonstrated the use of solvent additives for refining the morphology of one-step slot-die coated $\mathrm{CH}_{3} \mathrm{NH}_{3} \mathrm{PbI}_{3}$ perovskite films in a P-I-N device stack with PEDOT:PSS HTL and PCBM ETL [49]. 5vol\% of N-cyclohexyl-2-pyrrolidone (CHP) along with 6vol\% of dimethyl sulfoxide (DMSO) was mixed in with the $0.75 \mathrm{M}$ perovskite DMF solvent system precursor ink. Fourier-transform infrared spectroscopy (FTIR) results showed adduct formation between $\mathrm{PbI}_{2}$ and DMSO and that this was dominant over that with DMF and CHP. The high polarity and high basicity of DMSO compared to that of DMF 


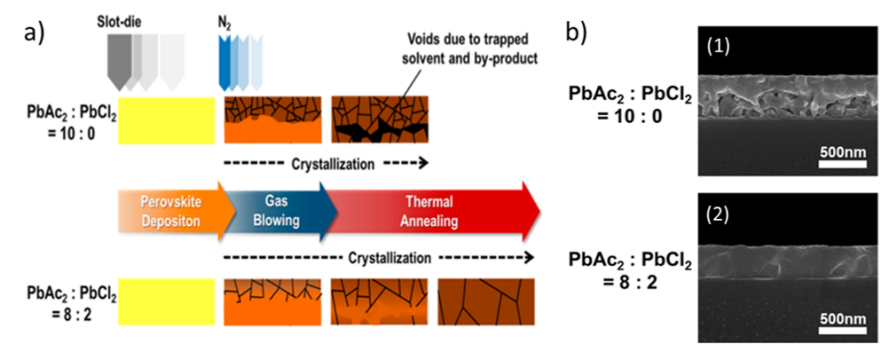

Figure 5: (a) Schematic representation of the crystallization of perovskite films. (b) SEM images showcasing the voids formed by rapid crystallization of perovskite and the same being mitigated by addition of $\mathrm{PbCl}_{2}$. Adapted with permission from ref [45]. Copyright 2018, American Chemical Society.

and CHP were found to be the reason for this behavior. The adduct formation with DMSO mainly retarded the crystallization rate of perovskite films. Interestingly CHP having the high boiling point and low vapour pressure likely remained in the solidifying film and assisted in uniform nucleation growth. Together the combined effects of these result in uniform and ho- ${ }^{478}$ mogenous perovskite films that consequently resulted in better performance. Moreover the binary additive was found to play a $a^{48}$ role in preferentially oriented crystal growth of perovskite films which again helped in better charge transport [50].

PCEs of around $18 \%$ with slot die coating have been achieved by making use of DMF and N-Methyl-2-Pyrrolidone ${ }_{485}$ (NMP) $[33,51]$. However, the high toxicity of DMF and $\mathrm{NMP}_{486}$ limits its usage in manufacturing process. A safer alternative was developed by Noel et al. wherein the composite of ace- ${ }_{487}$ tonitrile (ACN) with methylamine gas was developed to dis- ${ }_{488}$ solve MAI and $\mathrm{PbI}_{2}$ [52]. Due to the low boiling point and high ${ }_{489}$ volatility of ACN, $98 \%$ of crystallization was noted (after $\sim 110_{490}$ sec) at room temperature. The rapid crystallization of the $\mathrm{ACN}_{491}$ based formulation and lower toxicity, relative to DMF, fit well ${ }_{492}$ into the criteria for its use in large area fabrication and the $\operatorname{low}_{493}$ viscosity potentially means high slot-die coating speeds can be $\mathrm{e}_{494}$ attained. Dou et al. implemented this formulation for slot-die ${ }_{495}$ coating, in a R2R fabrication process using a flexible indium ${ }_{496}$ zinc oxide coated glass substrate and a N-I-P device stack, with ${ }_{497}$ slot-die coated tin oxide ETL [20]. The optimized R2R process ${ }_{498}$ led to the formation of uniaxially oriented crystalline $\operatorname{smooth}_{499}$ perovskite films. A hero PCE of $14.12 \%$ was reported for $\mathrm{R}_{2} \mathrm{R}_{500}$ and $17.31 \%$ for S2S slot-die coated films, Figure 6 . While the ${ }_{501}$ ACN formulation is suitable for large area deposition, it could ${ }_{502}$ be argued that high flammability and still considerable toxicity ${ }_{503}$ of this solvent system might hinder its commercial use.

Alternatively, DMSO is another less toxic solvent for use in 505 large area manufacturing of PSCs. The solvent itself is con-506 sidered low toxicity but it is able to easily penetrate the skin 507 along with any solute dissolved in it. However, with proper 508 safety precautions it is an attractive option. Unfortunately, the 509 poor wetting of DMSO on most substrates makes it quite dif-510 ficult to print with good film coverage. Galagan et al. demon-511 strated the addition of $10 \% \mathrm{vol} / \mathrm{vol} 2$-Butoxyethanol in $\mathrm{DMSO}_{512}$ to lower the surface tension of the solvent mixture. This im-513 proved wetting and achieved improved film coverage [19]. In n $_{514}$

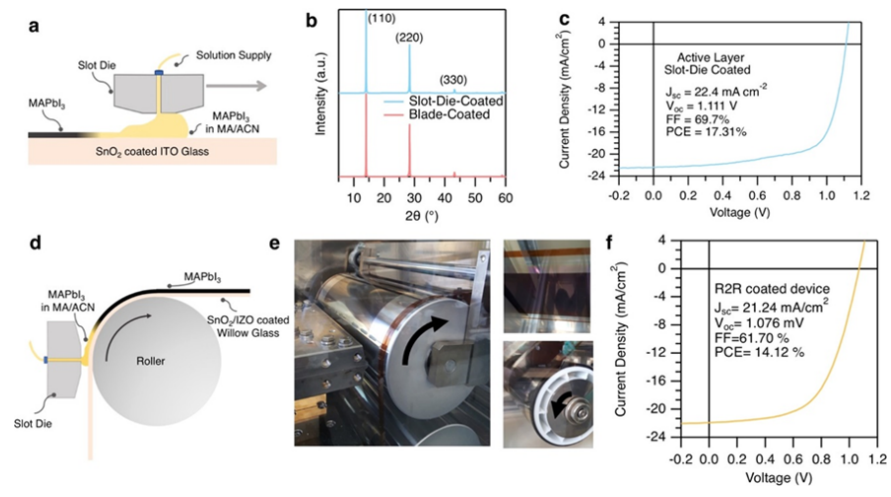

Figure 6: (a-c) Schematic illustration of slot-die coating process on rigid substrate (a) XRD (b) JV data (c). (d) Schematic illustration of slot-die coating process on flexible glass substrate with $R 2 R$ process. (e) Images showing $R 2 R$ coating (f) JV curve of the best performing R2R-coated device. Adapted with permission from ref [20]. Copyright 2018, American Chemical Society.

a R2R process, using a flexible ITO coated PET substrate and N-I-P device stack, using a slot-die coated tin oxide layer and a slot-die coated $\mathrm{Cs}_{0.15} \mathrm{FA}_{0.85} \mathrm{PbI}_{2.85} \mathrm{Br}_{0.15}$ perovskite layer the best performing device demonstrated a PCE of $15.2 \%$ over an active area of $0.09 \mathrm{~cm}^{2}$ and a stabilised PCE of $13.5 \%$.

Modification of solvent systems offers a powerful tool to control the perovskite film morphology and has resulted in high performance R2R devices, but careful consideration needs to be given to the suitability of such systems for industrial manufacture.

\subsubsection{Controlling Film Formation Through Additives and Sur- face Modification}

Additives have played a large role in improving the stability and efficiency of PSCs by influencing crystal growth and the morphology of perovskite films [53]. Zuo et al. used a $\mathrm{NH}_{4} \mathrm{Cl}$ additive to improve the perovskite film quality in a $\mathrm{CH}_{3} \mathrm{NH}_{3} \mathrm{PbI}_{3}$ perovskite formulation in DMF with small additions of $\mathrm{NH}_{4} \mathrm{Cl}$ using a P-I-N device stack with PEDOT:PSS HTL and PCBM ETL [17]. Absorption spectroscopy confirmed the higher absorption of light by the active layer in the presence of $\mathrm{NH}_{4} \mathrm{Cl}$. Additionally higher photoluminescence intensity was observed in the films with $\mathrm{NH}_{4} \mathrm{Cl}$, confirming mitigation in non-radiative recombination and film defects. For slotdie coated devices the use of a $\mathrm{NH}_{4} \mathrm{Cl}$ additive was combined with heating of the substrate and gas blowing, yielding highquality perovskite films for both S2S glass substrate devices and R2R devices on flexible PET substrate. Notably the fabrication was carried out at $45 \%$ relative humidity demonstrating a hero cell performance of $15.57 \%$ PCE for S2S coated devices and $11.16 \%$ PCE with R2R coated devices.

A different approach to improve perovskite film morphology and reduce defects is by surface treating interlayers. In one such work, by Gu et al., 3-aminopropanoic acid as an ambipolar selfassembled monolayer (C3-SAM) was introduced for the modification of PEDOT:PSS [54]. Using a P-I-N device stack with $\mathrm{CH}_{3} \mathrm{NH}_{3} \mathrm{PbI}_{3-x} \mathrm{Cl}_{x}$ perovskite formulation, PEDOT:PSS HTL and PCBM/ZnO ETL, C3-SAM was applied to the PEDOT:PSS film. The modified PEDOT:PSS helped in better perovskite film 

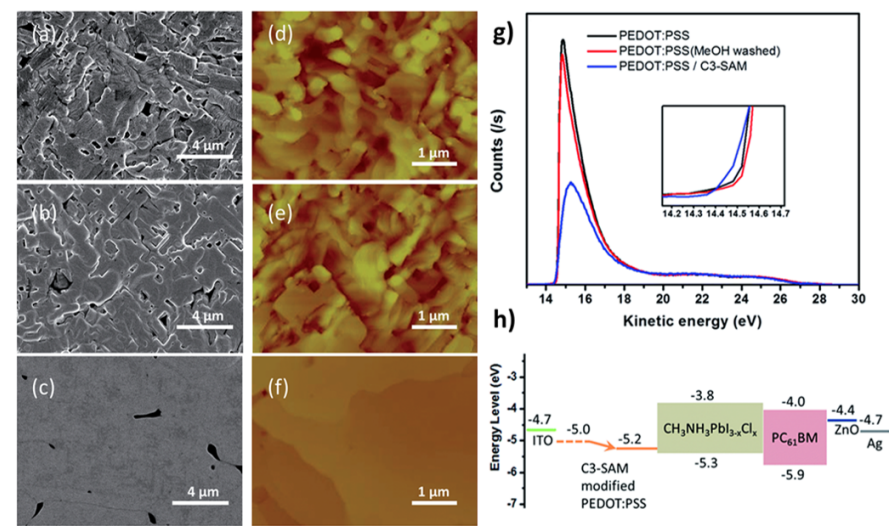

Figure 7: SEM (a-c) and AFM (d-f) images of $\mathrm{CH}_{3} \mathrm{NH}_{3} \mathrm{PbI}_{3-x} \mathrm{Cl}_{x}$ films on the as-prepared PEDOT:PSS (a and d), methanol washed PEDOT:PSS ( $b$ and e) and C3-SAM modified PEDOT:PSS (c and f). (g) The ultraviolet photoelectron spectroscopy (UPS) spectra of the as-prepared PEDOT:PSS (black line), methanol washed PEDOT:PSS (red line) and C3-SAM modified PEDOT:PSS (blue line). (h) The energy band alignment of PSCs. Reproduced with permission from ref [54] Copyright 2015, Royal Society of Chemistry.

growth but also had a positive effect on the energy band alignment by inducing an extra permanent dipole. It was further confirmed by UV photoelectron spectroscopy, that the treatment of C3-SAM lowered the work function of PEDOT:PSS by $0.2 \mathrm{eV}$, Figure 7, the improvement in charge transport and film morphology led to the hero PCE of 5.1\% on flexible S2S roll coated PSCs.

Recently, Kim et al. introduced polyethylene ox $^{549}$ ide (PEO) as an additive in slot-die coated perovskite films, using a P-I-N stack with modified PEDOT:PSS HTL, $\quad\left(\mathrm{CH}_{3} \mathrm{NH}_{3}\right)_{0.6}\left(\mathrm{HC}\left(\mathrm{NH}_{2}\right)_{2}\right)_{0.38} \mathrm{Cs}_{0.2} \mathrm{PbI}_{2.975} \mathrm{Br}_{0.025} \quad$ and $_{552}$ PCBM/PEIE ETL and evaporated Ag top electrode [55]. This was used in conjunction with using $\mathrm{PbCl}_{2}$ as the source of ${ }_{555}$ chloride as an additive and with deposition of the perovskite ${ }_{55}$ ink onto a heated substrate. The polymer additive was found $d_{557}^{556}$ to improve the tolerance of perovskite to deposition in high humidity (approx. 55\% RH) conditions and resulted in clear changes to performance, Figure 8. This novel method for the fabrication of PSCs in ambient conditions has the potential of ${ }_{558}$ driving manufacturing cost further down, an important step towards commercialization. Notably it's the only fully R2R (except top contact) processed PSC reported so far, showing an $_{559}$ impressive efficiency of $11.7 \%$.

\section{2D Perovskite Layers} proved lifetime compared to 3D perovskites [56]. 2D per-565 ovskites are typically prepared by introducing a large organic 566 molecule (for example butylammonium) in between the layers567 of 3D perovskite. Previously the performance of the PSCs with 568 2D perovskite have been quite low compared to 3D perovskite, 569 however they have significantly improved in the past few years570 and have recently achieved $14.1 \%$ PCE [57]. Excellent lifetime 571 and improvement in the performance of $2 \mathrm{D}$ perovskite based $\mathrm{d}_{52}$ PSCs has encouraged their use with large area printing and 573
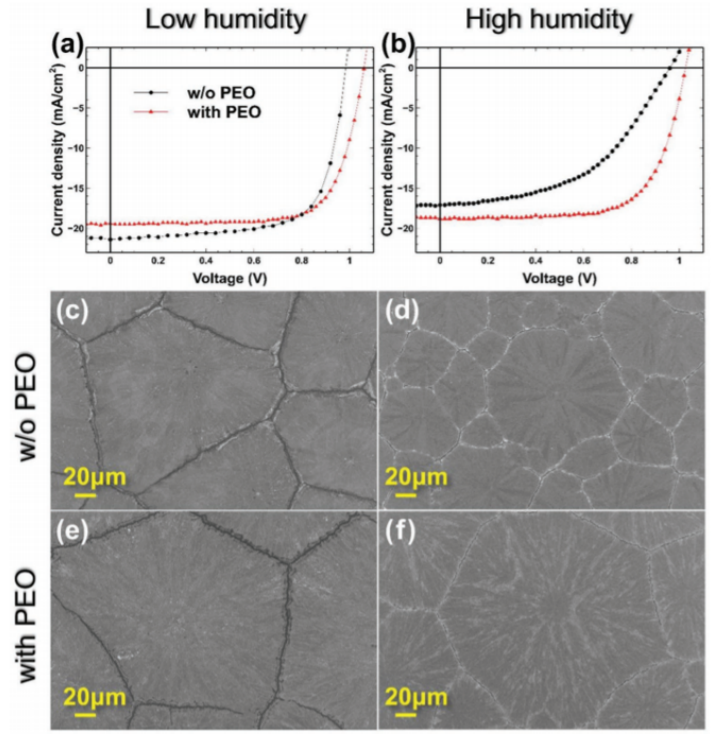

Figure 8: Comparison of device performance and surface morphology with and without PEO at in a low $(30 \pm 5 \% \mathrm{RH})$ and high $(55 \pm 5 \% \mathrm{RH})$ humidity coating environment. JV curves of the slot-die coated devices in (a) low and (b) high humidity, SEM images of perovskite films on glass/ITO/m-PEDOT:PSS substrates w/o PEO deposited in (c) low and (d) high humidity, and with PEO deposited at (e) low and (f) high humidity. Reproduced with permission from ref [55]. Copyright 2019, Wiley.

coating techniques. Fu et al. first demonstrated R2R printed 2D perovskite reporting an impressive PCE of $8 \%$ on plastic substrate and $12.5 \%$ by batch coating on glass substrate [58]. Loss in performance in the R2R printed device compared to spin coated device (14.9\% PCE) was attributed to mediocre film quality by R2R slot-die deposition due to less hydrophilic surface of ITO/PET. However, it is an encouraging report with the first ever R2R coated 2D perovskite and shows progress for large area 2D perovskite PSCs.

\section{Interlayers}

Although it is important to perfect the deposition of the perovskite layer, it is also vital to achieve the same with charge transport layers. Defects in the coatings can be detrimental to device performance through various processes; voids and pinholes can cause shunt leakages and lead to shorts, poor charge blocking capabilities can lead to increases in recombination of charge carriers. In addition to this, temperature limitations must be overcome for coating onto temperature sensitive substrates such as PET, where a maximum processing temperature of $140^{\circ} \mathrm{C}$ is required. This significantly hinders the deposition of the more common solution processed ETLs such as; tin oxide $\left(\mathrm{SnO}_{2}\right)$ from tin chloride $\left(\mathrm{SnCl}_{4} \cdot 2 \mathrm{H}_{2} \mathrm{O}\right)$ [59], NiOx from nickel (II) acetate tetrahydrate, and $\mathrm{TiO}_{2}$ from titanium diisopropoxide bis (acetylacetonate) [60], which require much higher annealing temperatures of $300^{\circ} \mathrm{C}$ and above. 


\subsection{Tin Oxide Electron Transport Layer}

Tin oxide $\left(\mathrm{SnO}_{2}\right)$ has gained significant usage as an ETL in ${ }^{60}$ perovskite devices, due to its high electron mobility, better band ${ }^{631}$ alignment with perovskite when compared to $\mathrm{TiO}_{2}$ and unlike ${ }^{632}$ $\mathrm{TiO}_{2}$ it doesn't induce serious UV degradation [40]. Therefore, ${ }^{633}$ $\mathrm{SnO}_{2}$ is a strong candidate for an ETL in devices in terms of ${ }^{634}$ both performance and stability. The use of $\mathrm{SnO}_{2}$ is well estab ${ }^{635}$ lished in small area devices, with the majority of reports em- ${ }^{-636}$ ploying a tin (IV) chloride precursor [40, 59]. Although this ${ }^{637}$ precursor requires a relatively low temperature anneal at $180^{\circ} \mathrm{C},{ }^{638}$ it is still too high to be compatible with common flexible sub- ${ }^{639}$ strates e.g. PET, in addition a long annealing time of around ${ }^{640}$ one hour is required.

Recently the use of $\mathrm{SnO}_{2}$ formulations for low-temperature ${ }^{642}$ $\mathrm{R} 2 \mathrm{R}$ depositions with excellent device performance have been $^{643}$ reported. Galagan et al. [19] and Bu et al. [61] used a col $^{644}$ loidal suspension of tin (IV) oxide $15 \%$ wt./vol in $\mathrm{H}_{2} \mathrm{O}$ (Alfa ${ }^{645}$ Aesar), which can be dried at $140-150^{\circ} \mathrm{C}$ in a shorter period ${ }^{646}$ of time. Galagan et al. employed this $\mathrm{SnO}_{2}$ solution into a $\mathrm{R}^{6} \mathrm{R}^{647}$ N-I-P stack, in which the solution was diluted with $10 \mathrm{vol} \%$ 1-butanol to aid wetting and slot-die coated at $5 \mathrm{~m} / \mathrm{min}$, with ${ }^{648}$ subsequent drying at $140^{\circ} \mathrm{C}$ in a $20 \mathrm{~m}$ length oven at the same $e^{649}$ speed. Perovskite was also R2R coated, with the subsequent ${ }^{650}$ spiro-OMeTAD and gold contacts deposited offline, achieving ${ }^{61}$ a hero cell reverse scan PCE of $15.2 \%$ and a stabilised PCE of ${ }^{652}$ $13.5 \%$. Bu et al. also used this $\mathrm{SnO}_{2}$ solution for use in bench ${ }^{653}$ top S2S slot-die coating for devices and modules on ITO coated ${ }^{654}$ PET substrate. The colloidal suspension was diluted with IPA ${ }^{655}$ in a 1:1 ratio to aid in the wetting of the ink on the substrate..$^{656}$ Three slot-die coatings of the ink were made to build up the film ${ }^{657}$ thickness and improve uniformity, followed by drying at $140^{\circ} \mathrm{C}^{658}$ for 60 minutes. Such a long drying time is unattractive for high ${ }^{659}$ throughput R2R coating, however, Galagan et al. showed that ${ }^{660}$ this drying time can be reduced to a few minutes. $\mathrm{Bu}$ et al. ${ }^{661}$ highlighted the fact that the $\mathrm{KOH}$ stabilizing agent in the $\mathrm{SnO}_{2}{ }^{662}$ solution also passivates the perovskite/ $\mathrm{SnO}_{2}$ interface leading ${ }^{663}$ to enhanced efficiency and stability. The rest of the device stack ${ }^{664}$ in this case was spin-coated but does however prove the compatibility of this $\mathrm{SnO}_{2}$ solution with a slot-die coating process ${ }^{66}$ capable of producing high efficiency devices and modules with ${ }^{666}$ PCEs of $17.18 \%$ for small area devices and an impressive $15 \%{ }^{667}$ for a $5 \times 6 \mathrm{~cm}^{2}$ flexible module.

\subsection{Zinc Oxide Electron Trasport Layer}

Slot-die coated Zinc Oxide ( $\mathrm{ZnO})$ layers have been widely ${ }_{672}$ used in organic photovoltaic devices [62]. Hwang K et al. used673 this knowledge and made a fully R2R coated perovskite device,674 apart from evaporated contacts, using a $\mathrm{ZnO}$ nanoparticle solu-675 tion made in house [16]. No difference was noted when com-676 paring the slot-die coated zinc oxide to the spin coated equiva-677 lent. Slot-die coated zinc oxide layers required a relatively short678 drying time of 10 minutes at $120^{\circ} \mathrm{C}$, demonstrating compatibil-679 ity with a $\mathrm{R} 2 \mathrm{R}$ processes on temperature sensitive substrates.680 However, zinc oxide has been reported on numerous occasions681 to cause stability problems with perovskite devices and induce 682 rapid degradation of the perovskite layer. It is well reported that 683 thermal annealing of perovskite on top of $\mathrm{ZnO}$ causes the perovskite to decompose and is due to the basic properties of the $\mathrm{ZnO}$, causing deprotonation of the methyl ammonium cations.

Krebs et al. also used low-temperature $\left(110^{\circ} \mathrm{C}\right)$ dried, slotdie coated $\mathrm{ZnO}$ on flexible ITO coated PET substrates with $\mathrm{N}$ I-P device stack, with a PCBM interlayer between the $\mathrm{ZnO}$ and perovskite [27]. Krebs et al. also found that annealing the perovskite precursor on top of the $\mathrm{ZnO}$ caused issues with perovskite formation, and overcame this by using a two-step perovskite deposition, which gave a champion efficiency of $2.6 \%$. Although the device performance is relatively low due to the use of a printed top electrode, it does demonstrate the compatibility of $\mathrm{ZnO}$ in a R2R compatible process.

The instability of $\mathrm{ZnO}$ based devices can, to an extent, be reduced by depositing the $\mathrm{ZnO}$ on top of the perovskite, usually using a nanoparticle formulation, firstly by negating the need for thermal annealing of the perovskite on the $\mathrm{ZnO}$ surface, and secondly as $\mathrm{ZnO}$ has a strong resistance to oxygen and humidity [63].

\subsection{Titanium Dioxide Electron Transport Layer}

Slot-die coating of the $\mathrm{TiO}_{2}$ blocking layer has been achieved by Burkitt et al., but required sintering at $550^{\circ} \mathrm{C}$ for an extended period, which is not low-temperature substrate compatible. In order to achieve an adequate blocking layer the solvent system for the titanium diisopropoxide bis (acetylacetonate) precursor was optimised and two coatings of the layer made, one on top of the other in an attempt to fill pin-holes and coating defects [42]. More recently Hossain et al. have reported the use of $\mathrm{TiO}_{2}$ nanoparticles for a low-temperature coatable blocking layer processed at $100^{\circ} \mathrm{C}$. As the nanoparticles are presynthesised in the anatase phase, high temperature annealing is avoided. Using these nanoparticles Hossain et al. achieved a stabilised efficiency of $15.7 \%$ using slot-die coating or alternatively the same efficiency was achieved using inkjet printing of the layer, demonstrating the potential for low temperature $\mathrm{TiO}_{2}$ slot-die coating formulations [64].

\subsection{Hole Transport Layers}

Slot-die coating of HTLs in PSCs has been reported for both P-I-N and N-I-P device stacks. For the P-I-N stack the most common of these is PEDOT:PSS, the slot-die coating of which has been well developed for organic photovoltaics; modified PEDOT:PSS layers for slot-die coating have been reported $[17,65]$ to improve the energy level alignment with perovskite, but nonetheless PEDOT:PSS is still seen as an unattractive HTL due to stability issues. Zuo et al. reported on slot-die coating of reduced graphene oxide as a replacement for PEDOT:PSS that resulted in improved performance and could be a potentially attractive HTL for large area PSCs [17, 66]. Metal oxide HTLs, such as nickel oxide ( $\mathrm{NiOx}$ ) are seen as potentially more stable alternatives to PEDOT:PSS and in a conference proceeding report from Giacomo et al. slot-die coating of NiOx was reported, but a comprehensive explanation of the processing conditions has not yet been given [67].

For the N-I-P device stack slot-die coating of spiro-MeOTAD was reported by Burkitt et al. [42] where the use of a highly 
toxic chlorobenzene solvent system was avoided by replacing this with less toxic toluene, but the stability issues of spiroOMeTAD are still unattractive for the use of this HTL in large area depositions. Qin et al. reported the replacement of spiroMeOTAD with bifluo-OMeTAD, that forms amorphous films and avoids the formation of large crystallites that worsen the performance of spiro-OMeTAD films, this resulted in a high performance of $14.7 \%$ PCE for devices with slot-die coated ETL, perovskite and HTL.

The use of P3HT as a slot-die coated HTL has also been reported for both S2S and R2R devices, but has generally resulted in lower performance or been used in conjunction with another evaporated HTL $[16,18]$.

Slot-die coating of HTLs is a relatively understudied area of research and in particular the reports on the deposition of more ${ }^{736}$ stable materials and metal oxides is scarce.

\section{Contacts}

In PSCs transparent conductive oxides (TCO) have been the ${ }^{74}$ preferred choice for transparent electrode (hereafter referred as ${ }_{743}$ bottom electrode) mainly because of its good electrical conductivity and high transparency. TCOs are widely used across ${ }_{745}$ several industries for various applications like smart windows, touchscreens, organic light emitting diodes, liquid crystal displays and antistatic coatings. Given their commercial use, they ${ }^{74}$ have been well optimized for large scale production. However, they still contribute to over $70 \%$ of the total cost of PSCs. Look- ${ }^{747}$ ing at alternatives, Sears et al demonstrated TCO free slot die ${ }^{748}$ printed transparent electrode for PSCs by replacing tin doped ${ }^{74}$ indium oxide by Ag/PEDOT:PSS achieving PCE of 11\%.[68].

For top contact, high vacuum thermal evaporation is typically ${ }^{75}$ used for lab scale fabrication which basically is a bottle neck ${ }^{752}$ for cost effective high through put manufacturing. Printing the solution processed top electrode is not trivial for number of rea- ${ }^{754}$ sons. Ideal top electrode would have high conductivity which ${ }^{755}$ can be processed at low temperature and the processing solu- ${ }^{756}$ tion must be orthogonal to all the layers underneath. To realize ${ }^{757}$ complete solution processed PSCs, solutions like fully printed ${ }^{758}$ mesoscopic PSCs[10] and printable top electrodes have been ${ }^{759}$ proposed.[69]. However, till date to the best of our knowledge ${ }^{760}$ no reports are available showcasing the slot die printing of top ${ }^{76}$ electrode in PSCs. Other techniques like ink-jet [70] and spray ${ }^{762}$ coating[69] have been implemented to print silver nanowire as ${ }^{763}$ top electrode.

\section{Module Representation}

Good performance has been reported so far on slot-die coated z PSCs, however, this has been demonstrated mostly for smalli70 area devices with small aperture masks used for testing. It is 771 equally important to showcase the performance of large area 72 printed PSCs to assess its potential for manufacture and actual 773 power generation. The first slot-die coated perovskite module 774 was reported by Hwang $\mathrm{K}$ et al. with $40 \mathrm{~cm}^{2}$ active area but 75 the performance was poor and not reported fully [16]. Later in ${ }_{776}$ a)
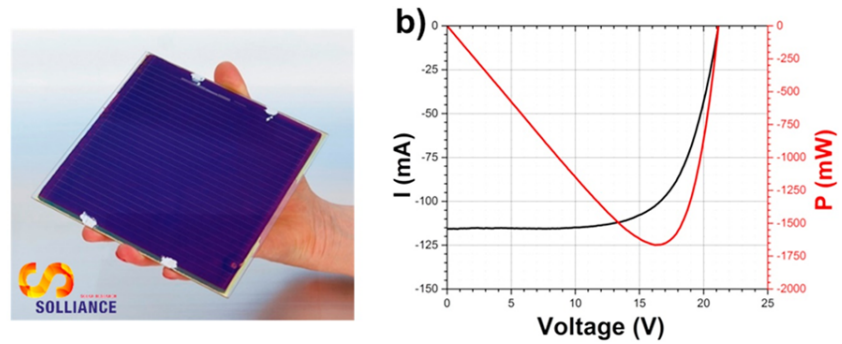

Figure 9: (a) -6 in. by 6 in. perovskite module; (b) - IV curve and power curve of the 6 in. by 6 in. module, with the actual module dimension of $168.75 \mathrm{~cm}^{2}$, containing 25 interconnected cells. Reproduced with permission from ref [48]. Copyright 2017, Elsevier.

2018, Lee et al. reported the use of mixed Pb precursors, Section 2.2.2, for the fabrication of large area PSCs. This strategy was successfully implemented for module fabrication attaining $8.3 \%$ PCE on $10 \mathrm{~cm}^{2}$ area [45], it is to be noted that only perovskite was printed via slot-die coating in this report. Following this, Giacomo et al. demonstrated a module, Figure 9, with PCE of $10 \%$ on a 6-inch substrate with an active area of $168.75 \mathrm{~cm}^{2}$, notably the one-step perovskite and HTL were both printed by slot-die coating while the ETL was deposited by electron beam deposition [48].

\section{Outlook and Perspectives}

Slot-die coating has proven to be a powerful tool for the deposition of perovskite films for both high performance small area devices and large area modules, it is also one of the only techniques to have been used for the demonstration of R2R fabrication of perovskite solar cells. A great deal of effort has been directed at developing strategies for controlling the formation of the perovskite layer, both in terms of achieving a high rate of nucleation to facilitate the formation of films with high surface coverage and in controlling the crystallisation and crystal growth of the perovskite to achieve large grain sizes with good interconnection and orientation. These have been achieved using a variety of methods including drying regimes, precursors and additives, surface modifications and solvent systems, as well as by separating the perovskite deposition process out into multiple steps. In most cases combinations of these methods have been combined and adapted to the particular set of processing conditions used.

To date the two most promising slot-die perovskite methods reported are the R2R demonstrations from Dou et al. [20] and Galagan et al. [19]. The use of the ACN:MA solvent system in the work of Dou et al. demonstrates the great potential of this system for the easy deposition of high quality perovskite films that dry rapidly and are deposited from a low viscosity solvent system. But, along with the toxicity of $\mathrm{ACN}$ the other downside to this system is that it has been reported that caesium ions show poor solubility in this system and Cs containing perovskites have been reported as some of the most stable and high performing perovskites. The work of Galagan et al. demonstrates the potential for the deposition of mixed cation and anion perovskites, in particular containing caesium and the use 
of lower toxicity solvent systems based on DMSO, but DMSO is relatively low volatility and achieving good film formation and rapid drying is not trivial. Both works show great promise for the development of slot-die coating fabrication methods and finding ways to achieve the best of both in one system seems a highly desirable target. In particular, achieving a rapid drying low viscosity solvent system that is also able to deliver Cs ions but avoids the use of toxic ACN would overcome some of the hurdles to demonstrating a reliable industrially relevant R2R coating process.

Both of these works have also shown the use of $\mathrm{SnO}_{2}$ ETLs, deposited by slot-die coating, the work of Dou et al. using a higher temperature process and the work of Galagan et al. demonstrating the use of a lower temperature process. $\mathrm{SnO}_{2}$ appears to be a clear leader for the development of slot-die coatable ETL formulations, using low cost precursors that require low deposition temperatures and result in high performance and stable devices. Further developing $\mathrm{SnO}_{2}$ formulations to improve both the coating properties and electronic properties of the films is a sound progression for ETL development. Deposition of HTLs using slot-die coating is an under explored area and worthy of further study, the coating method seems well adapted to this and is likely to be the method of choice for R2R compatible coatings of these materials seen in the future. Slot-die coating has potential for deposition of other layers in the device stack, such as transparent conductive films and electrodes, but the lack of full 2D patterning might limit this to certain device stacks. As well as photovoltaics there are other technologies where slot-die coating of perovskites has been reported, including photodetectors [71] and PeLEDs [72] and developments in these areas are likely to also be relevant to photovoltaics.

\section{Acknowledgements}

This work was supported by the Engineering and Physical Sciences Research Council (EPSRC) through SPECIFIC Innovation and Knowledge Centre (EP/N020863/1 and $\mathrm{EP} / \mathrm{P} 030831 / 1)$. This project has received funding from the European Union's Horizon 2020 research and innovation programme under the Marie Sklodowska-Curie grant agreement No 764787. The authors would like to acknowledge the financial support provided by the M2A that has been made possible through funding from the European Social Fund via the Welsh Government, the Engineering and Physical Sciences Research Council (EP/L015099/1) and Tata Steel Europe that has made this research possible. 


\begin{tabular}{|c|c|c|c|c|c|c|c|c|c|c|c|c|}
\hline No. & Type & Device Stack & Key Concept & $\begin{array}{l}\text { Scan } \\
\text { Direction }\end{array}$ & $\begin{array}{c}\text { Active Area } \\
\left(\mathrm{cm}^{2}\right) \\
\end{array}$ & $\begin{array}{l}\text { Voc } \\
\text { (V) }\end{array}$ & $\begin{array}{c}\mathrm{Jsc} \\
\left(\mathrm{mAcm}^{-2}\right) \\
\end{array}$ & $\begin{array}{l}\mathrm{FF} \\
(\%) \\
\end{array}$ & $\begin{array}{l}\text { PCE } \\
(\%) \\
\end{array}$ & $\begin{array}{c}\text { Stabilised PCE } \\
(\%) \\
\end{array}$ & $\begin{array}{c}\text { Hero PCE } \\
(\%) \\
\end{array}$ & Refere \\
\hline 1. & S2S & $\begin{array}{l}\text { PET/ITO/ZnO/PCBM/CH }{ }_{3} \mathbf{N H}_{3} \mathbf{P b I}_{3} / \mathbf{P 3 H T} / \mathbf{P E D O T : P S S / A g ~} \\
\text { PET/ITO/PEDOT:PSS/CH } \mathbf{C H}_{3} \mathbf{N H}_{3} \mathbf{P b I}_{3-x} \mathbf{C l}_{x} / \mathbf{P C B M} / \mathbf{Z n O} / \mathrm{Ag}\end{array}$ & $\begin{array}{l}\text { Comparison of one } \\
\text { and two-step methods }\end{array}$ & $\begin{array}{l}\text { NS } \\
\text { NS }\end{array}$ & $\begin{array}{l}0.2-0.5 \\
0.2-0.5\end{array}$ & $\begin{array}{l}0.69 \\
0.88\end{array}$ & 4.6 & 47 & 1.6 & NS & 2.6 & {$[27$} \\
\hline 2. & S2S & Glass $/ \mathrm{ITO} / \mathbf{Z n O} / \mathbf{C H}_{3} \mathbf{N H}_{3} \mathbf{P b I}_{3} / \mathbf{P 3 H T} / \mathrm{Ag}$ & $\begin{array}{l}\text { Lead iodide film for- } \\
\text { mation }\end{array}$ & NS & 0.1 & 0.95 & 19.9 & 54 & 10.1 & NS & 11.96 & {$[16$} \\
\hline 3. & S2S & PET/ITO/PEDOT:PSS/CH ${ }_{3} \mathbf{N H}_{3} \mathbf{P b I}_{3-x} \mathbf{C l}_{x} / \mathbf{P C B M} / \mathrm{Au}$ & Substrate Heating & Reverse & 0.12 & 0.68 & 9.6 & 33 & 2.4 & NS & 2.91 & \\
\hline 4. & S2S & Glass/FTO/c- $-\mathrm{TiO}_{2} / \mathrm{m}-\mathrm{TiO}_{2} / \mathbf{C H}_{3} \mathbf{N H}_{3} \mathbf{P b I}_{3-x} \mathbf{C l}_{x} / \mathrm{Spiro}-\mathrm{OMeTAD} / \mathrm{Au}$ & $\begin{array}{l}\text { Heated substrate and } \\
\text { air-knife }\end{array}$ & Reverse & 0.062 & 0.78 & 14.9 & 66 & 7.0 & 8.1 & 9.2 & {$[41$} \\
\hline 5. & S2S & $\begin{array}{c}\text { Glass/ITO/PEDOT:PSS/CH } \mathbf{C H}_{3} \mathbf{N H}_{3} \mathbf{P b I}_{3} / \mathbf{P C B M} / \mathrm{BCP} / \mathrm{Ag} \\
\text { Glass/ITO/FrGo/ } \mathbf{C H}_{3} \mathbf{N H}_{3} \mathbf{P b I} \mathbf{I}_{3} / \mathbf{P C B M} / \mathrm{BCP} / \mathrm{Ag}\end{array}$ & Solvent additives & $\begin{array}{l}\text { NS } \\
\text { NS }\end{array}$ & $\begin{array}{l}0.1 \\
0.1\end{array}$ & $\begin{array}{r}0.87 \\
1.0\end{array}$ & $\begin{array}{l}14.3 \\
16.3\end{array}$ & $\begin{array}{l}77 \\
76\end{array}$ & $\begin{array}{c}9.57 \\
12.52\end{array}$ & $\begin{array}{l}\text { NS } \\
\text { NS }\end{array}$ & $\begin{array}{c}9.57 \\
12.52\end{array}$ & {$[49$} \\
\hline 6. & $\begin{array}{l}\text { R2R } \\
\text { R2R } \\
\text { R2R }\end{array}$ & 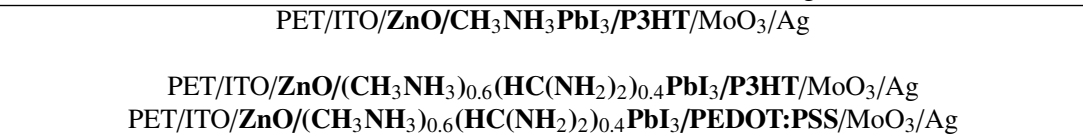 & $\begin{array}{l}\text { Intra-additive sequen- } \\
\text { tial deposition } \\
\text { Mixed cations }\end{array}$ & $\begin{array}{l}\text { NS } \\
\text { NS } \\
\text { NS }\end{array}$ & $\begin{array}{l}0.1 \\
0.1\end{array}$ & $\begin{array}{l}0.93 \\
1.04\end{array}$ & $\begin{array}{l}12.3 \\
14.4 \\
19.6\end{array}$ & $\begin{array}{l}54 \\
54\end{array}$ & $\begin{array}{l}7.25 \\
11.0\end{array}$ & $\begin{array}{l}\text { NS } \\
\text { NS }\end{array}$ & $\begin{array}{l}7.25 \\
11.0\end{array}$ & {$[18$} \\
\hline 7. & S2S & Glass/FTO/SnO2/ $/ \mathbf{C H}_{3} \mathbf{N H}_{3} \mathbf{P b I} / 3$ Spiro-OMeTAD/Au & $\begin{array}{l}\text { Mediator Extraction } \\
\text { Treatment }\end{array}$ & Reverse & 0.096 & 1.11 & 21.9 & 76 & 17.3 & NS & 18.3 & {$[3$.} \\
\hline 8. & S2S & Glass/ITO/SnO $2 / \mathbf{C H}_{3} \mathbf{N H}_{3} \mathbf{P b I}_{3-x} \mathbf{C l} \mathbf{l}_{x} /$ Spiro-OMeTAD/Au & $\begin{array}{l}\text { Solvent and precursor } \\
\text { additives }\end{array}$ & Reverse & 0.06 & 1.1 & 21.5 & 76 & 18.0 & 15.6 & 18.0 & {$[51$} \\
\hline 9. & S2S & $\mathrm{PET} / \mathrm{ITO} / \mathbf{Z n O} / \mathbf{C H}_{3} \mathbf{N H}_{3} \mathbf{P b I}_{3} / \mathbf{P 3 H T} / \mathrm{Au}$ & Surface treatments & Reverse & 1.0 & NS & NS & NS & 1.6 & NS & 3.6 & {$[35$} \\
\hline 10. & $\begin{array}{l}\mathrm{S} 2 \mathrm{~S} \\
\mathrm{R} 2 \mathrm{R}\end{array}$ & $\begin{array}{l}\text { PET/ITO/modified-PEDOT:PSS/CH } \mathbf{C H}_{3} \mathbf{N H}_{3} \mathbf{P b I}_{3-x} \mathbf{C l}_{x} / \mathrm{PCBM} / \mathrm{Ca} / \mathrm{Al} \\
\text { PET/ITO/modified-PEDOT:PSS/CH} \mathbf{C H}_{3} \mathbf{N H}_{3} \mathbf{P b I}_{3-x} \mathbf{C l}_{x} / \mathrm{PCBM} / \mathrm{Ca} / \mathrm{Al}\end{array}$ & $\begin{array}{l}\text { Use of } \mathrm{NH}_{4} \mathrm{Cl} \text { addi- } \\
\text { tive }\end{array}$ & $\begin{array}{l}\text { Reverse } \\
\text { Reverse }\end{array}$ & $\begin{array}{l}0.1 \\
0.1\end{array}$ & $\begin{array}{l}1.02 \\
0.98\end{array}$ & $\begin{array}{l}19.8 \\
17.4\end{array}$ & $\begin{array}{l}77 \\
65\end{array}$ & $\begin{array}{l}15.57 \\
11.16\end{array}$ & $\begin{array}{c}15.17 \\
\text { NS }\end{array}$ & $\begin{array}{l}15.57 \\
11.16\end{array}$ & {$[17$} \\
\hline 11. & $\mathrm{~S} 2 \mathrm{~S}$ & $\begin{array}{c}\text { Glass/ITO/PEDOT:PSS/C } \mathbf{C H}_{3} \mathbf{N H}_{3} \mathbf{P b I}_{3-x} \mathbf{C l}_{x} / \mathrm{PCBM} / \mathrm{BCP} / \mathrm{Ag} \\
4 \text { cell module with same structure }\end{array}$ & Mixed lead precursors & NS & $\begin{array}{c}0.1 \\
10.0\end{array}$ & $\begin{array}{c}0.88 \\
3.8\end{array}$ & $\begin{array}{c}16.6 \\
4.1\end{array}$ & $\begin{array}{l}78 \\
52\end{array}$ & $\begin{array}{c}11.4 \\
8.3\end{array}$ & $\begin{array}{l}\text { NS } \\
\text { NS }\end{array}$ & $\begin{array}{c}13.3 \\
8.3\end{array}$ & {$[45$} \\
\hline 12. & S2S & 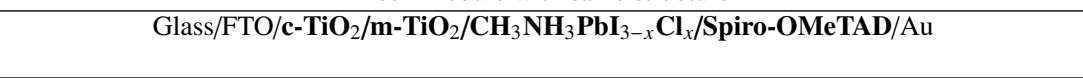 & $\begin{array}{l}\text { Four layers in N-I-P } \\
\text { stack slot-die coated. }\end{array}$ & Reverse & 0.09 & 0.8 & 15.8 & 46 & 5.73 & 7 & 11.9 & {$[42$} \\
\hline 13. & S2S & Glass/ITO/ZnO/ $\mathbf{C H}_{3} \mathbf{N H}_{3} \mathbf{P b I} /$ /Bifluo-OMeTAD/Ag & $\begin{array}{l}\text { Blowing and heating } \\
\text { of perovskite film }\end{array}$ & Reverse & 0.1 & 1.10 & 17.21 & 67.25 & 11.10 & NS & 12.73 & {$[43$} \\
\hline 14. & S2S & $\begin{array}{c}\text { Glass/ITO/TiO2/CH} \mathbf{C H}_{3} \mathbf{N H}_{3} \mathbf{P b I} I_{3-x} \mathbf{C l}_{x} / \mathbf{S p i r o - O M e T A D} / \mathrm{Au} \\
25 \text { cell module with same structure. }\end{array}$ & Large area module & $\begin{array}{l}\text { NS } \\
\text { NS }\end{array}$ & $\begin{array}{c}0.09 \\
151.87 *\end{array}$ & $\begin{array}{l}1.03 \\
21.2\end{array}$ & $\begin{array}{l}22.1 \\
17.3\end{array}$ & $\begin{array}{c}74 \\
68\end{array}$ & $\begin{array}{l}16.8 \\
11.1\end{array}$ & $\begin{array}{c}14 \\
\text { NS }\end{array}$ & $\begin{array}{l}16.8 \\
11.1\end{array}$ & {$[48$} \\
\hline 15. & $\begin{array}{l}\mathrm{S} 2 \mathrm{~S} \\
\mathrm{R} 2 \mathrm{R}\end{array}$ & 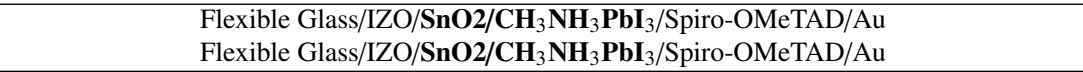 & ACN:MA solvent & $\begin{array}{l}\text { Reverse } \\
\text { Reverse }\end{array}$ & $\begin{array}{l}0.15 \\
0.15\end{array}$ & $\begin{array}{l}1.11 \\
1.08\end{array}$ & $\begin{array}{l}22.4 \\
21.2\end{array}$ & $\begin{array}{l}70 \\
62\end{array}$ & $\begin{array}{l}17.31 \\
14.12\end{array}$ & $\begin{array}{l}15.6 \\
\text { NS }\end{array}$ & $\begin{array}{l}17.31 \\
14.12\end{array}$ & {$[20$} \\
\hline 16. & S2S & Glass/FTO/c-TiO $2 / \mathbf{m}-\mathbf{T i O}_{2} / \mathbf{C H}_{3} \mathbf{N H}_{3} \mathbf{P b I}_{3} /$ Spiro-OMeTAD/Au & $\mathrm{PbI}_{2}$ in DMSO & $\begin{array}{l}\text { Reverse } \\
\text { Forward }\end{array}$ & $\begin{array}{l}0.09 \\
0.09\end{array}$ & $\begin{array}{l}0.96 \\
0.95\end{array}$ & $\begin{array}{l}16.7 \\
15.2\end{array}$ & $\begin{array}{l}67 \\
59\end{array}$ & $\begin{array}{c}11.0 \\
8.7\end{array}$ & $\begin{array}{l}\text { NS } \\
\text { NS }\end{array}$ & $\begin{array}{l}13.2 \\
10.6\end{array}$ & {$[36$} \\
\hline 17. & R2R & $\mathrm{PET} / \mathrm{ITO} / \mathbf{S n O} 2 / \mathbf{C s}_{0.15}\left(\mathbf{H C}\left(\mathbf{N H}_{2}\right)_{2}\right)_{0.85} \mathbf{P b I}_{2.85} \mathbf{B r}_{0.15} /$ Spiro-OMeTAD/Au & $\begin{array}{lrr}\text { Mixed cation } & \text { and } \\
\text { DMSO with } & 2- \\
\text { butoxyethanol } & \end{array}$ & Reverse & 0.09 & 1.03 & 20.7 & 72 & 15.2 & 13.5 & 15.2 & {$[19$} \\
\hline 18. & S2S & Glass/ITO/PEDOT:PSS/ $\mathbf{C H}_{3} \mathbf{N H}_{3} \mathbf{P b I}_{3} / \mathrm{PCBM} / \mathrm{PEI} / \mathrm{Ag}$ & NIR heating & NS & 0.3 & 0.98 & 18.4 & 67 & 12.0 & NS & 12.3 & {$[34$} \\
\hline 19. & R2R & PET/ITO/m-PEDOT:PSS/(CH$\left.{ }_{3} \mathbf{N H}_{3}\right)_{0.6}\left(\mathbf{H C}\left(\mathbf{N H}_{2}\right)_{2}\right)_{0.38} \mathbf{C s}_{0.2} \mathbf{P b I}_{2.975} \mathbf{B r}_{0.025} / \mathbf{P C B M} / \mathbf{P E I E} / \mathrm{Ag}$ & PEO additive & Reverse & 0.1 & 0.93 & 20.3 & 45 & 8.62 & NS & 11.67 & {$[55$} \\
\hline 20. & $\mathrm{~S} 2 \mathrm{~S}$ & PET/ITO/PEDOT:PSS/CH $\mathbf{C H}_{3} \mathbf{N H}_{3} \mathbf{P b I}_{3} / \mathbf{P C B M} / \mathrm{Ag}$ & $\mathrm{Pb}$ precursor & Forward & 0.1 & 0.96 & 15.9 & 35 & 5 & NS & 6.5 & {$[47$} \\
\hline 21. & S2S & PET/ITO/PEDOT:PSS/C3-SAM/ $\mathbf{C H}_{3} \mathbf{N H}_{3} \mathbf{P b I}_{3-x} \mathbf{C l}_{x} / \mathbf{P C B M} / \mathbf{Z n O} / \mathrm{Ag}$ & Surface modification & Forward & 0.05 & 0.98 & 13.7 & 38 & 5.1 & NS & 5.1 & {$[54$} \\
\hline 22. & $\begin{array}{l}\mathrm{S} 2 \mathrm{~S} \\
\mathrm{R} 2 \mathrm{R}\end{array}$ & $\begin{array}{l}\left.\text { Glass/ITO/PEDOT:PSS/(CH} \mathbf{C H}_{3}\left(\mathbf{C H}_{2}\right)_{3} \mathbf{N H}_{3}\right)_{2}\left(\mathbf{C H}_{3} \mathbf{N H}_{3}\right)_{3} \mathbf{P b}_{4} \mathbf{I}_{13} / \mathrm{PCBM} / \mathrm{PEIE} / \mathrm{Ag} \\
\text { PET/ITO/PEDOT:PSS/(CH} 3\left(\mathbf{C H}_{3}\left(\mathbf{C H}_{2}\right)_{3} \mathbf{N H}_{3}\right)_{2}\left(\mathbf{C H}_{3} \mathbf{N H}_{3}\right)_{3} \mathbf{P b}_{4} \mathbf{I}_{13} / \mathrm{PCBM} / \mathrm{PEIE} / \mathrm{Ag}\end{array}$ & 2D Perovskite & $\begin{array}{l}\text { Forward } \\
\text { Forward }\end{array}$ & $\begin{array}{l}0.1 \\
0.1\end{array}$ & $\begin{array}{l}1.06 \\
1.02\end{array}$ & $\begin{array}{l}16.6 \\
13.6\end{array}$ & $\begin{array}{l}71 \\
58\end{array}$ & $\begin{array}{c}12.5 \\
8.0\end{array}$ & $\begin{array}{l}\text { NS } \\
\text { NS }\end{array}$ & $\begin{array}{r}12.5 \\
8.0\end{array}$ & {$[58$} \\
\hline 23. & R2R & $\mathrm{PEN} / \mathrm{ITO} / \mathrm{SnO}_{2} / \mathrm{PbI}_{2}-\mathrm{CsI} / \mathbf{H C}\left(\mathbf{N H}_{2}\right)_{2} \mathbf{I}-\mathbf{C H}_{3} \mathbf{N H}_{3} \mathbf{I} / \mathrm{Spiro}-\mathrm{OMeTAD} / \mathrm{Ag}$ & Two step mixed cation & NS & 0.07 & 0.98 & 16.82 & 64 & 9.97 & 9.8 & 10.57 & \\
\hline
\end{tabular}

Note:

Table 1: Device stacks and JV scan photovoltaic parameters of slot-die coated perovskite devices reported in the literature so far.

1. Bold font indicates slot-die coated layer in the device stack.

2. The performance parameters (Voc, Jsc, FF and PCE) are the average values. Italic font is used if the mean values were not available and represents the parameters of hero cell and not mean values.

3. * The active area was calculated by multiplying the geometric fill fcator with that of substrate area.

4. R2R is a process involving transfer of substrates between two moving rolls. Therefore reports using just rollers, essentially roll coating are also termed as S2S. 


\section{References}

[1] A. Kojima, K. Teshima, Y. Shirai, T. Miyasaka, Organometal halide ${ }^{894}$ perovskites as visible-light sensitizers for photovoltaic cells, Journal ${ }_{896}$ of the American Chemical Society 131 (2009) 6050-6051. URL: https://doi.org/10.1021/ja809598r. doi:10.1021/ja809598r. ${ }_{898}$ arXiv:https://doi.org/10.1021/ja809598r, pMID: 19366264. 899

2] Best research-cell efficiency chart, https://www.nrel.gov/pv/assets/pdfs/beştresearch-cell-efficiencies-190416.pdf, 2019. Accessed: 28/05/2019.

[3] M. M. Lee, J. Teuscher, T. Miyasaka, T. N. Murakami, H. J.901 Snaith, Efficient hybrid solar cells based on meso-superstructured ${ }_{903}$ organometal halide perovskites, Science 338 (2012) 643-647. URL: ${ }_{904}$ https://science.sciencemag.org/content/338/6107/643. 905 doi:10.1126/science.1228604. arXiv: https://science. sciencemag go $_{0}$

[4] H.-S. Kim, C.-R. Lee, J.-H. Im, K.-B. Lee, T. Moehl, A. Marchioro, S.-J.907 Moon, R. Humphry-Baker, J.-H. Yum, J. E. Moser, et al., Lead iodide ${ }_{908}$ perovskite sensitized all-solid-state submicron thin film mesoscopic solar ${ }_{909}$ cell with efficiency exceeding 9\%, Scientific reports 2 (2012) 591.

[5] D. B. Mitzi, C. Feild, W. Harrison, A. Guloy, Conducting tin halides with ${ }_{911}^{910}$ a layered organic-based perovskite structure, Nature 369 (1994) 467.

[6] J. E. Carlé, M. Helgesen, O. Hagemann, M. Hösel, I. M.913 Heckler, E. Bundgaard, S. A. Gevorgyan, R. R. Søndergaard, ${ }_{914}$ M. Jørgensen, R. García-Valverde, S. Chaouki-Almagro, ${ }_{915}$ J. A. Villarejo, F. C. Krebs, Overcoming the scaling $\operatorname{lag}_{916}$ for polymer solar cells, Joule 1 (2017) 274 - 289. URL: ${ }_{917}$ http://www.sciencedirect.com/science/article/pii/S25424351 doi:https://doi.org/10.1016/j.joule.2017.08.002.

[7] P. Sommer-Larsen, M. Jørgensen, R. R. Søndergaard, M. Hösel, ${ }_{920}^{919}$ F. C. Krebs, It is all in the pattern-high-efficiency power $r_{921}$ extraction from polymer solar cells through high-voltage se- ${ }_{922}$ rial connection, Energy Technology 1 (2013) 15-19. URL: ${ }_{923}$ https://onlinelibrary.wiley.com/doi/abs/10.1002/ente.2012200055 doi:10.1002/ente.201200055. arXiv: https://onlinelibrary. wiley ey ${ }_{925} \mathrm{om} / \mathrm{do}$

[8] N. Espinosa, M. Hösel, M. Jørgensen, F. C. Krebs, Large ${ }_{926}$ scale deployment of polymer solar cells on land, on $\mathrm{sea}_{927}$ and in the air, Energy Environ. Sci. 7 (2014) 855866. URL: http://dx.doi.org/10.1039/C3EE43212B. ${ }_{929}$ doi:10.1039/C3EE43212B.

[9] Y. Deng, E. Peng, Y. Shao, Z. Xiao, Q. Dong, J. Huang, Scalable ${ }_{931}^{930}$ fabrication of efficient organolead trihalide perovskite solar cells $\mathrm{s}_{932}$ with doctor-bladed active layers, Energy Environ. Sci. 8 (2015) 1544-1550. URL: http://dx.doi.org/10.1039/C4EE03907F. doi:10.1039/C4EE03907F.

[10] A. Mei, X. Li, L. Liu, Z. Ku, T. Liu, Y. Rong, M. Xu, ${ }_{936}^{935}$ M. Hu, J. Chen, Y. Yang, M. Grätzel, H. Han, A holeconductor-free, fully printable mesoscopic perovskite solar ${ }_{938}$ cell with high stability, Science 345 (2014) 295-298. URL: $:_{939}$ https://science.sciencemag.org/content/345/6194/295. doi:10.1126/science.1254763. arXiv: https://science. sciencemag ${ }_{949}^{940} \mathrm{r}$

[11] J. E. Bishop, T. J. Routledge, D. G. Lidzey, $\mathrm{Ad}_{942}$ vances in spray-cast perovskite solar cells, The Jour- $_{943}$ nal of Physical Chemistry Letters 9 (2018) 1977-1984.944 URL: $\quad$ https://doi.org/10.1021/acs.jpclett.8b00311. ${ }_{945}$ doi:10.1021/acs.jpclett.8b00311. arXiv : https://doi .org/10.1021/34cs pMID: 29608061

[12] H. Huang, J. Shi, L. Zhu, D. Li, Y. Luo, Q. Meng, Two-step ${ }^{947}$ ultrasonic spray deposition of ch3nh3pbi3 for efficient and large- ${ }_{949}$ area perovskite solar cell, Nano Energy 27 (2016) 352 - 358. URL: $:_{950}$ http://www.sciencedirect.com/science/article/pii/S221128555 doi:https://doi.org/10.1016/j.nanoen.2016.07.026.

[13] Y. Y. Kim, T.-Y. Yang, R. Suhonen, M. Välimäki, T. Maaninen, A. Kemppainen, N. J. Jeon, J. Seo, Gravure-printed ${ }_{954}$ flexible perovskite solar cells: Toward roll-to-roll manu- ${ }_{955}$ facturing, Advanced Science 6 (2019) 1802094. URL: $:_{956}$ https://onlinelibrary.wiley.com/doi/abs/10.1002/advs.2018020 doi:10.1002/advs.201802094. arXiv: https://onlinelibrary. wiley 55 cop 2 dp

[14] C. Momblona, L. Gil-Escrig, E. Bandiello, E. M. Hutter, M. Ses- ${ }_{959}$ solo, K. Lederer, J. Blochwitz-Nimoth, H. J. Bolink, Efficient ${ }_{960}$ vacuum deposited $\mathrm{p}-\mathrm{i}-\mathrm{n}$ and $\mathrm{n}$-i-p perovskite solar cells employ- ${ }_{961}$ ing doped charge transport layers, Energy Environ. Sci. 9 (2016) 3456-3463. URL: http://dx.doi.org/10.1039/C6EE02100J. ${ }_{963}$ doi:10.1039/C6EE02100J.
[15] Y. Deng, X. Zheng, Y. Bai, Q. Wang, J. Zhao, J. Huang, Surfactantcontrolled ink drying enables high-speed deposition of perovskite films for efficient photovoltaic modules, Nature Energy 3 (2018) 560-566. URL: https://doi.org/10.1038/s41560-018-0153-9. doi:10.1038/s41560-018-0153-9.

[16] K. Hwang, Y.-S. Jung, Y.-J. Heo, F. H. Scholes, S. E. Watkins, J. Subbiah, D. J. Jones, D.-Y. Kim, D. Vak, Toward large scale roll-to-roll production of fully printed perovskite solar cells, Advanced Materials 27 (2015) 1241-1247. URL: https://onlinelibrary.wiley.com/doi/abs/10.1002/adma.201404598. doi:10.1002/adma.201404598. arXiv:https://onlinelibrary.wiley.com/do

[17] C. Zuo, D. Vak, D. Angmo, L. Ding, M. Gao, Onestep roll-to-roll air processed high efficiency perovskite so-

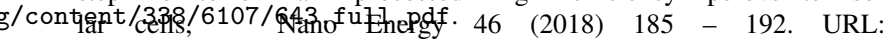
http://www.sciencedirect.com/science/article/pii/S2211285518300 doi:https://doi.org/10.1016/j.nanoen.2018.01.037.

[18] Y.-J. Heo, J.-E. Kim, H. Weerasinghe, D. Angmo, T. Qin, K. Sears, K. Hwang, Y.-S. Jung, J. Subbiah, D. J. Jones, M. Gao, D.-Y. Kim, D. Vak, Printing-friendly sequential deposition via intra-additive approach for roll-to-roll process of perovskite solar cells, Nano Energy 41 (2017) 443 - 451. URL: http://www.sciencedirect.com/science/article/pii/S2211285517305 doi:https://doi.org/10.1016/j.nanoen.2017.09.051

[19] Y. Galagan, F. Di Giacomo, H. Gorter, G. Kirchner, I. de Vries, R. Andriessen, P. Groen, Roll-to-roll slot die coated perovskite for efficient 02722 ible solar cells, Advanced Energy Materials 8 (2018) 1801935. URL: https://onlinelibrary.wiley.com/doi/abs/10.1002/aenm. 201801935. doi:10.1002/aenm.201801935. arXiv:https://onlinelibrary.wiley.com/do

[20] B. Dou, J. B. Whitaker, K. Bruening, D. T. Moore, L. M. Wheeler, J. Ryter, N. J. Breslin, J. J. Berry, S. M. Garner, F. S. Barnes, S. E. Shaheen, C. J. Tassone, K. Zhu, M. F. A. M. van Hest, Roll-to-roll printing of perovskite solar cells, ACS Energy Letters 3 (2018) 2558-

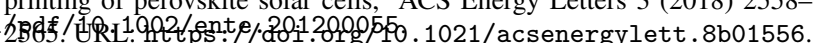
doi:10.1021/acsenergylett.8b01556. arXiv: https://doi.org/10.1021/acsene

[21] D. Burkitt, P. Greenwood, K. Hooper, D. Richards, V. Stoichkov, D. Beynon, E. Jewell, T. Watson, Meniscus guide slot-die coating for roll-to-roll perovskite solar cells, MRS Advances 4 (2019) 1399-1407. doi:10.1557/adv.2019.79.

[22] M. S. Carvalho, H. S. Kheshgi, Low-flow limit in slot coating: Theory and experiments, AIChE Journal 46 (2000) 1907-1917. URL: https://aiche.onlinelibrary.wiley.com/doi/abs/10.1002/aic.69046 doi:10.1002/aic.690461003. arXiv:https://aiche.onlinelibrary.wiley.con

[23] X. Ding, J. Liu, T. A. L. Harris, A review of the operating limits in slot die coating processes, AIChE Journal 62 (2016) 2508-2524. URL: https://aiche.onlinelibrary.wiley.com/doi/abs/10.1002/aic.15268. doi:10.1002/aic.15268. arXiv: https : //aiche. onlinelibrary. wiley.com/do

[24] K. Liang, D. B. Mitzi, M. T. Prikas, Synthesis and characterization of organic-inorganic perovskite thin films prepared using a versatile two等 https://doi.org/10.1021/cm970568f. doi:10.1021/cm970568f. arXiv:https://doi.org/10.1021/cm970568f

[25] J. Burschka, N. Pellet, S.-J. Moon, R. Humphry-Baker, P. Gao, M. K. Nazeeruddin, M. Grätzel, Sequential deposition as a route to high. jpcleptetfơolphan 31 1 perovskite-sensitized solar cells, Nature 499 (2013) 316 EP -. URL: https://doi.org/10.1038/nature12340.

[26] N. J. Jeon, J. H. Noh, Y. C. Kim, W. S. Yang, S. Ryu, S. I. Seok, Solvent engineering for high-performance inorganic-organic hybrid perovskite solar cells, Nature Materials 13 (2014) 897 EP -. URL: 16302658 tps://doi.org/10.1038/nmat4014, article.

[27] T. M. Schmidt, T. T. Larsen-Olsen, J. E. Carlé, D. Angmo, F. C. Krebs, Upscaling of perovskite solar cells: Fully ambient roll processing of flexible perovskite solar cells with printed back electrodes, Advanced Energy Materials 5 (2015) 1500569. URL: https://onlinelibrary.wiley.com/doi/abs/10.1002/aenm.201500569.

4. doi:10.1002/aenm.201500569. arXiv: https://onlinelibrary.wiley.com/do

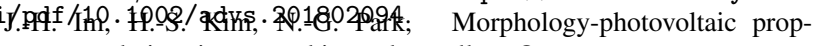
erty correlation in perovskite solar cells: One-step versus two-step deposition of ch3nh3pbi3, APL Materials 2 (2014) 081510. URL: https://doi.org/10.1063/1.4891275. doi:10.1063/1.4891275. arXiv:https://doi.org/10.1063/1.4891275.

[29] J. A. Baker, Y. Mouhamad, K. E. A. Hooper, D. Burkitt, M. Geoghe- 
gan, T. M. Watson, From spin coating to roll-to-roll: investigating the 035 challenge of upscaling lead halide perovskite solar cells, IET Renewable 036 Power Generation 11 (2017) 546-549. doi:10.1049/iet-rpg.2016.0683. 1037

[30] T. Zhang, M. Yang, Y. Zhao, K. Zhu, Controllable sequen ${ } 038$ tial deposition of planar ch3nh3pbi3 perovskite films via ad+039 justable volume expansion, Nano Letters 15 (2015) 3959-39631040 URL: https://doi.org/10.1021/acs.nanolett.5b008431041 doi:10.1021/acs.nanolett.5b00843. arXiv : https ://doi .org/10.10210Aacs pMID: 25996160

[31] Y. Xie, F. Shao, Y. Wang, T. Xu, D. Wang, F. Huang, Enhanced perfort044 mance of perovskite ch3nh3pbi3 solar cell by using ch3nh3i as additive 045 in sequential deposition, ACS Applied Materials \& Interfaces 7 (2015)046 12937-12942. URL: https://doi.org/10.1021/acsami.5b027051047 doi:10.1021/acsami.5b02705. arXiv: https ://doi.org/10.1021/acs pMID: 26009927

[32] C. Gong, S. Tong, K. Huang, H. Li, H. Huang, J. Zhang, J. Yang, Flexiblecoso planar heterojunction perovskite solar cells fabricated via sequential roll +05 to-roll microgravure printing and slot-die coating deposition, Solar RRL1052 (????).

[33] Y. Y. Kim, E. Y. Park, T.-Y. Yang, J. H. Noh, T. J. Shin, N. J1054 Jeon, J. Seo, Fast two-step deposition of perovskite via me 4055 diator extraction treatment for large-area, high-performance 056 perovskite solar cells, J. Mater. Chem. A 6 (2018) 12447+057 12454. URL: http://dx.doi.org/10.1039/C8TA02868K1058 doi:10.1039/C8TA02868K.

[34] Y.-C. Huang, C.-F. Li, Z.-H. Huang, P.-H. Liu, C.-S Tsao, Rapid and sheet-to-sheet slot-die coating manufac 4061 ture of highly efficient perovskite solar cells processed un*062 der ambient air, Solar Energy 177 (2019) 255 - 261. URL1063 http://www.sciencedirect.com/science/article/pii/S00380®2 doi:https://doi.org/10.1016/j.solener.2018.11.020.

[35] M. Remeika, L. K. Ono, M. Maeda, Z. Hu, Y. Qi, High 7066 throughput surface preparation for flexible slot die coated per*067 ovskite solar cells, Organic Electronics 54 (2018) 72 - 79. URL1068 http://www.sciencedirect.com/science/article/pii/S156611ف9 doi:https://doi.org/10.1016/j.orgel.2017.12.027.

[36] D. Burkitt, J. Searle, D. A. Worsley, T. Watson, Se+4071 quential slot-die deposition of perovskite solar cells using 072 dimethylsulfoxide lead iodide ink, Materials 11 (2018)1073 URL: $\quad$ http://www.mdpi.com/1996-1944/11/11/21061074 doi:10.3390/ma11112106.

37] T. A. Berhe, W.-N. Su, C.-H. Chen, C.-J. Pan, J.-H. Cheng, H.-M. Chen1076 M.-C. Tsai, L.-Y. Chen, A. A. Dubale, B.-J. Hwang, Organometal halide077 perovskite solar cells: degradation and stability, Energy Environ. Sci. 9078 (2016) 323-356. URL: http://dx .doi .org/10.1039/C5EE02733K1079 doi:10.1039/C5EE02733K.

[38] N. H. Tiep, Z. Ku, H. J. Fan, Recent advances inos improving the stability of perovskite solar cells, Ad+082 vanced Energy Materials 6 (2016) 1501420. URL1083 1420. mechanisms of ch3nh3pbi3 film formation in one-step depo-

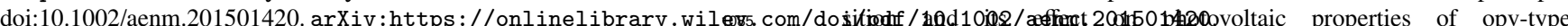

[39] M. P. de Jong, L. J. van IJzendoorn, M. J. A. de Voigt, Stat086 bility of the interface between indium-tin-oxide and poly $(3,4+087$ ethylenedioxythiophene)/poly(styrenesulfonate) in polymer light+088 emitting diodes, Applied Physics Letters 77 (2000) 2255-2257. URLi089 https://doi.org/10.1063/1.1315344. doi:10.1063/1.13153441090 arXiv:https://doi.org/10.1063/1.1315344

40] Q. Jiang, X. Zhang, J. You, Sno2: A wonderful electron trans4092 port layer for perovskite solar cells, Small 14 (2018) 1801154. URL1093 https://onlinelibrary.wiley.com/doi/abs/10.1002/smll.20d9801 doi:10.1002/smll.201801154. arXiv: https ://onlinelibrary . wileygascom/do

[41] G. Cotella, J. Baker, D. Worsley, F. D. Rossi, C. Pleydell-Pearcesog6 M. Carnie, T. Watson, One-step deposition by slot-die coating of 097 mixed lead halide perovskite for photovoltaic applications, So+098 lar Energy Materials and Solar Cells 159 (2017) 362 - 369. URLi099 http://www.sciencedirect.com/science/article/pii/S09270208 doi:https://doi.org/10.1016/j.solmat.2016.09.013.

[42] D. Burkitt, J. Searle, T. Watson, Perovskite so+102 lar cells in $n$-i-p structure with four slot-die-coated lay $\$ 103$ ers, Royal Society Open Science 5 (2018) 172158. URLi104 ers, Royal Society Open Science 5 (2018) 172158. URL1104 doi:10.1039/C7TA01798G.
https://royalsocietypublishing.org/doi/abs/10.1098/rsos 10172158]. Z. Gu, L. Zuo, T. T. Larsen-Olsen, T. Ye, G. Wu, F. C. Krebs, doi:10.1098/rsos.172158. arXiv:https://royalsocietypublishing.org/doi

[43] J.-E. Kim, Y.-S. Jung, Y.-J. Heo, K. Hwang, T. Qin, D.-Y. Kim, D. Vak, Slot die coated planar perovskite solar cells via blowing and heating assisted one step deposition, Solar Energy Materials and Solar Cells 179 (2018) 80 - 86. URL: http://www.sciencedirect.com/science/article/pii/S0927024818300 doi:https://doi.org/10.1016/j.solmat.2018.02.003

$s[$ AmlandleCtrobbold843A. Mejía-Escobar, F. Jaramillo, Slot-die processing of flexible perovskite solar cells in ambient conditions, Solar Energy 150 (2017) 570 - 576. URL: http://www.sciencedirect.com/science/article/pii/S0038092X173037 doi:https://doi.org/10.1016/j.solener.2017.04.071.

[45] D. Lee, Y.-S. Jung, Y.-J. Heo, S. Lee, K. Hwang, Y.-J. Jeon, J.-E. b02R0正, J. Park, G. Y. Jung, D.-Y. Kim, Slot-die coated perovskite films using mixed lead precursors for highly reproducible and largearea solar cells, ACS Applied Materials \& Interfaces 10 (2018) 16133-16139. URL: https://doi.org/10.1021/acsami.8b02549. doi:10.1021/acsami.8b02549. arXiv: https ://doi .org/10.1021/acsami.8b02 pMID: 29668247

[46] W. Zhang, M. Saliba, D. T. Moore, S. K. Pathak, M. T. Hörantner, T. Stergiopoulos, S. D. Stranks, G. E. Eperon, J. A. Alexander-Webber, A. Abate, A. Sadhanala, S. Yao, Y. Chen, R. H. Friend, L. A. Estroff, thin-film formation and crystallization for efficient planar heterojunction solar cells, Nature Communications 6 (2015) 6142 EP -. URL: https://doi.org/10.1038/ncomms7142, article.

[47] C. Kamaraki, A. Zachariadis, C. Kapnopoulos, E. Mekeridis, C. Gravalidis, A. Laskarakis, S. Logothetidis, Efficient flexible printed perovskite solar cells based on lead ac1120 ate precursor, Solar Energy 176 (2018) 406 - 411. URL: http://www.sciencedirect.com/science/article/pii/S0038092X18310 doi:https://doi.org/10.1016/j.solener.2018.10.055.

[48] F. D. Giacomo, S. Shanmugam, H. Fledderus, B. J. Bruijnaers, W. J. Verhees, M. S. Dorenkamper, S. C. Veenstra, W. Qiu, R. Gehlhaar, 62B7Merckx, T. Aernouts, R. Andriessen, Y. Galagan, Up-scalable sheet-to-sheet production of high efficiency perovskite module and solar cells on 6-in. substrate using slot die coating, Solar Energy Materials and Solar Cells 181 (2018) 53 - 59. URL: http://www.sciencedirect.com/science/article/pii/S0927024817306 doi:https://doi.org/10.1016/j.solmat.2017.11.010, thin film solar cells and applications.

[49] Y.-S. Jung, K. Hwang, Y.-J. Heo, J.-E. Kim, D. Lee, C.-H. Lee, H.-I. Joh, J.-S. Yeo, D.-Y. Kim, One-step printable perovskite films fabricated under ambient conditions for efficient and reproducible solar cells, ACS Applied Materials \& Interfaces 9 (2017) 27832-27838. URL: https://doi.org/10.1021/acsami.7b05078. doi:10.1021/acsami.7b05078. arXiv: https://doi.org/10.1021/acsami.7b05 pMID: 28752996

50] S. Bae S. J. Han T. J Shin W. H Jo, Two different perovskite solar cells, J. Mater. Chem. A 3 (2015) 23964 23972. URL: http://dx.doi.org/10.1039/C5TA06870C. doi: $10.1039 /$ C5TA06870C.

[51] J. B. Whitaker, D. H. Kim, B. W. Larson, F. Zhang, J. J. Berry, M. F. A. M. van Hest, K. Zhu, Scalable slot-die coating of high performance perovskite solar cells, Sustainable Energy Fuels 2 (2018) 2442-2449. URL: http://dx.doi.org/10.1039/C8SE00368H. doi:10.1039/C8SE00368H.

527. N. K. Noel, S. N. Habisreutinger, B. Wenger, M. T. Klug, M. T. Hörantner,

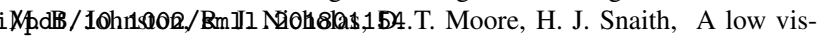
cosity, low boiling point, clean solvent system for the rapid crystallisation of highly specular perovskite films, Energy Environ. Sci. 10 (2017) 145-152. URL: http://dx.doi.org/10.1039/C6EE02373H. doi:10.1039/C6EE02373H. neering for highly efficient organic-inorganic halide perovskite solar cells: recent advances and perspectives, J. Mater. Chem. A 5 (2017) 12602-12652. URL: http://dx.doi.org/10.1039/C7TA01798G. U. Wiesner, H. J. Snaith, Ultrasmooth organic-inorganic perovskite

650135118Li, Y. Pan, Z. Wang, Y. Xia, Y. Chen, W. Huang, Additive engi- 
H. Chen, Interfacial engineering of self-assembled monolayer 177 modified semi-roll-to-roll planar heterojunction perovskite so+178 lar cells on flexible substrates, J. Mater. Chem. A 3 (2015) 179 24254-24260. URL: http://dx.doi.org/10.1039/C5TA07008B1180 doi:10.1039/C5TA07008B.

[55] J.-E. Kim, S.-S. Kim, C. Zuo, M. Gao, D. Vak, D.-Y. Kim1182 Humidity-tolerant roll-to-roll fabrication of perovskite so*183 lar cells via polymer-additive-assisted hot slot die deposi+184 tion, Advanced Functional Materials 0 (????) 1809194. URL1185 https://onlinelibrary.wiley.com/doi/abs/10.1002/adfm.2018809 doi:10.1002/adfm.201809194. arXiv : https ://onlinelibrary . wilej8\% com/do

[56] J. Yan, W. Qiu, G. Wu, P. Heremans, H. Chen, Re+188 cent progress in $2 \mathrm{~d}$ /quasi-2d layered metal halide perovskites 189 for solar cells, J. Mater. Chem. A 6 (2018) $11063+190$ 11077. URL: http://dx.doi.org/10.1039/C8TA02288G1191 doi:10.1039/C8TA02288G.

57] W. Fu, J. Wang, L. Zuo, K. Gao, F. Liu, D. S. Ginger,193 A. K.-Y. Jen, Two-dimensional perovskite solar cells with 194 $14.1 \%$ power conversion efficiency and $0.68 \%$ external radia +195 tive efficiency, ACS Energy Letters 3 (2018) 2086-20931196 URL: https://doi.org/10.1021/acsenergylett.8b011811197 doi:10.1021/acsenergylett.8b01181. arXiv:https://doi.org/10.102118 ac

58] C. Zuo, A. D. Scully, D. Vak, W. Tan, X. Jiao, C. R. McNeill, D. Angmo1199 L. Ding, M. Gao, Self-assembled 2d perovskite layers for efficient print $\$ 200$ able solar cells, Advanced Energy Materials 9 (2019) 1803258. URL1201 https://onlinelibrary.wiley.com/doi/abs/10.1002/aenm.2040803 doi:10.1002/aenm.201803258. arXiv: https ://onlinelibrary. wileys. com

[59] G. Murugadoss, H. Kanda, S. Tanaka, H. Nishino, S. Itoł204 H. Imahori, T. Umeyama, An efficient electron transport205 material of tin oxide for planar structure perovskite solar206 cells, Journal of Power Sources 307 (2016) 891 - 897. URL1207 http://www.sciencedirect.com/science/article/pii/S03787705 doi:https://doi.org/10.1016/j.jpowsour.2016.01.044.

[60] T. Supasai, N. Henjongchom, I.-M. Tang, F. Deng, N. Ru+210 jisamphan, Compact nanostructured tio2 deposited by aerosol211 spray pyrolysis for the hole-blocking layer in a ch3nh3pbi3 per 4212 ovskite solar cell, Solar Energy 136 (2016) 515 - 524. URL: http://www.sciencedirect.com/science/article/pii/S0038092X16302936. doi:https://doi.org/10.1016/j.solener.2016.07.035.

[61] T. Bu, J. Li, F. Zheng, W. Chen, X. Wen, Z. Ku, Y. Peng, J. Zhong, Y.-B. Cheng, F. Huang, Universal passivation strategy to slot-die printed sno2 for hysteresis-free efficient flexible perovskite solar module, Nature Communications 9 (2018) 4609. URL: https://doi.org/10.1038/s41467-018-07099-9. doi:10.1038/s41467-018-07099-9.

[62] R. R. Søndergaard, M. Hösel, F. C. Krebs, Roll-to-roll fabrication of large area functional organic materials, Journal of Polymer Science Part B: Polymer Physics 51 (2013) 16-34. URL: https://onlinelibrary.wiley.com/doi/abs/10.1002/polb.23192. doi:10.1002/polb.23192. arXiv:https://onlinelibrary.wiley.com/doi/pdf/10.1002/polb. 23192

[63] P. Zhang, J. Wu, T. Zhang, Y. Wang, D. Liu, H. Chen, L. Ji, C. Liu, W. Ahmad, Z. D. Chen, S. Li, Perovskite solar cells with zno electrontransporting materials, Advanced Materials 30 (2018) 1703737. URL: https://onlinelibrary.wiley.com/doi/abs/10.1002/adma. 201703737. doi:10.1002/adma.201703737. arXiv: https://onlinelibrary.wiley.com/doi/pdf/10.1002/adma. 201703737.

[64] I. M. Hossain, D. Hudry, F. Mathies, T. Abzieher, S. Moghadamzadeh, D. Rueda-Delgado, F. Schackmar, M. Bruns, R. Andriessen, T. Aernouts, F. Di Giacomo, U. Lemmer, B. S. Richards, U. W. Paetzold, A. Hadipour, Scalable processing of low-temperature tio2 nanoparticles for highefficiency perovskite solar cells, ACS Applied Energy Materials 2 (2019) 47-58. URL: https://doi.org/10.1021/acsaem.8b01567. doi:10.1021/acsaem.8b01567. arXiv: https ://doi.org/10.1021/acsaem.8b01567.

[65] C. Zuo, L. Ding, Modified pedot layer makes a $1.52 \mathrm{~V}$ voc for perovskite/pcbm solar cells, Advanced Energy Materials 7 (2017) 1601193. URL: https://onlinelibrary.wiley.com/doi/abs/10.1002/aenm. 201601193. doi:10.1002/aenm.201601193. arXiv: https://onlinelibrary.wiley.com/doi/pdf/10.1002/aenm. 201601193.

[66] J.-S. Yeo, C.-H. Lee, D. Jang, S. Lee, S. M. Jo, H.-I. Joh, D.-Y. Kim, Reduced graphene oxide-assisted crystallization of perovskite via solution-process for efficient and stable planar solar cells with module-scales, Nano Energy 30 (2016) 667 - 676. URL:
http://www.sciencedirect.com/science/article/pii/S22112855163048 doi:https://doi.org/10.1016/j.nanoen.2016.10.065.

67] F. D. Giacomo, H. Fledderus, H. Gorter, G. Kirchner, I. d. Vries, I. Dogan, W. Verhees, V. Zardetto, M. Najafi, D. Zhang, H. Lifka, Y. Galagan, T. Aernouts, S. Veenstra, P. Groen, R. Andriesse, Large area $i 140 \mathrm{~cm} 2$ perovskite solar modules made by sheet to sheet and roll to roll fabrication with $14.5 \%$ efficiency (2018) 2795-2798. doi:10.1109/PVSC.2018.8548157.

[68] K. K. Sears, M. Fievez, M. Gao, H. C. Weerasinghe, C. D. Easton, D. Vak, https://onlinelibrary.wiley.com/doi/abs/10.1002/solr.201700059. doi:10.1002/solr.201700059. arXiv:https://onlinelibrary.wiley.com/doi/

[69] F. Guo, H. Azimi, Y. Hou, T. Przybilla, M. Hu, C. Bronnbauer, S. Langner, E. Spiecker, K. Forberich, C. J. Brabec, Highperformance semitransparent perovskite solar cells with solutionprocessed silver nanowires as top electrodes, Nanoscale 7 (2015) 1642-1649. URL: http://dx.doi.org/10.1039/C4NR06033D. doi:10.1039/C4NR06033D.

[70] M. Xie, H. Lu, L. Zhang, J. Wang, Q. Luo, J. Lin, L. Ba, H. Liu, W. Shen, L. Shi, C.-Q. Ma, Fully solution-processed somilatatnspbent8perovskite solar cells with ink-jet printed silver nanowires top electrode, Solar RRL 2 (2018) 1700184. URL: https://onlinelibrary.wiley.com/doi/abs/10.1002/solr. 201700184. doi:10.1002/solr.201700184. arXiv: https://onlinelibrary.wiley.com/doi/

S. Tong, C. Gong, C. Zhang, G. Liu, D. Zhang, C. Zhou, flexible cesium-doped triple cation perovskite photodetector, Applied Materials Today 15 (2019) 389 - 397. URL: http://www.sciencedirect.com/science/article/pii/S2352940718307 doi:https://doi.org/10.1016/j.apmt.2019.03.001.

BDj041.Prakasam, D. Tordera, F. Di Giacomo, R. Abbel, A. Langen, G. Gelinck, H. J. Bolink, Large area perovskite light-emitting diodes by gas-assisted crystallization, J. Mater. Chem. C 7 (2019) 3795-3801. URL: http://dx.doi.org/10.1039/C8TC06482B. doi:10.1039/C8TC06482B. 